\title{
Finite Element Method for Active Vibration Suppression of Smart Composite Structures using Piezoelectric Materials
}

\author{
MeHrdad N. GHASEmi-NeJHAD, * SAEId PourJalali, \\ MARK UYEMA AND ALI YOUSEFPOUR \\ Intelligent and Composite Materials Laboratory \\ Department of Mechanical Engineering \\ University of Hawaii at Manoa \\ Honolulu, Hawaii 96822, USA
}

\begin{abstract}
Adaptive or intelligent structures which have the capability for sensing and responding to their environment promise a novel approach to satisfy the stringent performance requirements of future space missions. Analytical, numerical, and experimental results are employed to verify the performance of piezoelectric stacks and patches as well as to determine the natural frequencies of typical strut and panel structures. A strut model with a piezoelectric stack actuator for axial vibration suppression and a composite beam with surface-mounted piezoelectric patch actuator for lateral vibration suppression are considered to model an active composite strut (ACS) and an active composite panel (ACP), respectively. These ACS and ACP are employed to develop an actuator optimum voltage (OV) for active vibration suppression using modal, harmonic, and transient finite element analyses for a range of frequency encompassing a natural frequency. The ACP model demonstrates that the actuator vibration suppression capability depends on the modal shape and location of the actuator. The OV, in this work, is determined by increasing the level of actuator voltage gradually and generating a vibration with same frequencies as the external vibration but $180^{\circ}$ out-of-phase, and observing the increasing level of active vibration suppression until an optimum/threshold actuator voltage is reached. Beyond the optimum voltage level, the actuator increased the level of vibration $180^{\circ}$ out-of-phase. Modal, harmonic, and transient finite element analyses are performed to verify the results. Selected axial and lateral vibration suppression experiments are also performed to verify the numerical results. The analytical, numerical, and experimental results obtained in this work are in excellent
\end{abstract}

*Author to whom correspondence should be addressed. E-mail: nejhad@wiliki.eng.hawaii.edu Figures 2-9 and 11-39 appear in color online: http://jtc.sagepub.com

Journal of Thermoplastic COMPosite Materials, Vol. 19-May 2006 
agreements. This work also presents a systematic guideline for the use of piezoelectric stack and monolithic patch smart materials in intelligent structures using the finite element method.

KEY WORDS: active vibration suppression, smart composite structures, piezoelectric stacks and patches, finite element analysis, actuator optimum voltage, active composite struts and panels, axial and lateral vibration, actuator location effects.

\section{INTRODUCTION}

C URRENTLY PIEZOELECTRIC MATERIALS are being considered for use as both sensors and actuators for position and vibration control of structures. Materials, which exhibit piezoelectric behavior, generate a charge in response to a mechanical deformation or alternatively undergo a mechanical deformation in response to an applied electric field. This capability facilitates the use of these smart materials for either sensors or actuators in intelligent material systems and structures. Lead zirconate titanate (PZT) piezoelectric ceramic material is utilized as actuators in this application. Piezoelectric ceramic materials do not require radiation shielding and are fairly insensitive to temperatures unlike fiber optics or electrostrictive materials such as lead-magnesium-niobate (PMN) [1]. The inherent rigidity of piezoelectric ceramic materials (PZTs) also leads to a more efficient conversion of electrical energy into mechanical energy ensuring good actuation capabilities. Furthermore, the piezoelectric coupling between the elastic and dielectric phenomena is a relatively linear relationship between the mechanical and electrical behavior of the material that should simplify data acquisition and control of the structural response [2].

In terms of active struts, researchers have developed struts with vibration suppression or precision positioning capabilities. As previous work in terms of active struts, researchers developed active struts with vibration suppression capabilities [3-13]. Active struts have primarily been used for vibration suppression to maintain precision positioning rather than a direct precision positioning function. Most of the precision positioning of active strut systems has employed inchworm technology [13-20]. Ghasemi-Nejhad and co-workers [19-22] developed active composite struts (ACSs) with simultaneous vibration suppression and precision positioning capabilities.

In terms of active panels for vibration suppression, various researchers have worked on the embedded or surface-mounted sensors and actuators for composite and metallic plates, beams, and shells [23-31]. Researchers have shown that it is possible to tailor the shape/location of the actuator to either excite or suppress particular modes leading to improved control behavior. Active panels have also been used for precision positioning [32-34]. Also, researchers have studied the fatigue issues in active panels and their actuators [35-36]. Ghasemi-Nejhad and 
co-workers [21,37-40] have developed active composite panels (ACPs) with surface-mounted as well as embedded piezoelectric patches possessing simultaneous vibration suppression and precision positioning capabilities.

\section{Problem Statement}

This study aims at the determination of an actuator optimum peak voltage and the actuator location effects for active vibration suppression over a range of frequency encompassing a natural frequency using finite element method and employing (a) a representative model of an active composite strut (ACS) for axial vibration suppression utilizing piezoelectric ceramic material, PZT (lead-zirconate-titanate) with the designation of PZT-5A [41] as a stack actuator, and (b) an active composite panel (ACP) for lateral vibration suppression, utilizing piezoelectric ceramic material, PZT (lead-zirconate-titanate) with the designation of PZT-5A [41] as a surfacemounted monolithic patch actuator. The ACS and ACP are in fact building blocks of intelligent/adaptive structures [21]. The ACS can be used as active truss members, struts in Stewart and modified Stewart platforms [42,43], etc. The ACP can be incorporated as active members within space and aerospace structures such as micro-aerial-vehicles, MAV, [44], airplane wings [45-47], smart tails [48], helicopter blades, active panels [49-51], and strut housing $[19,20,52]$. These active members may have a dual role with both active vibration suppression and precision positioning capabilities. By proper design of the locations of the actuators, various modes of vibrations such as axial, lateral, etc. can be suppressed. An existing analytical solution is utilized to verify the finite element modal analysis for a simple structure. In addition, piezoelectric free expansion analytical, numerical, and experimental results are compared for both stack and monolithic patch actuators and excellent results are obtained. Furthermore, guidelines for the use of piezoelectric stack and monolithic patch smart materials in smart structures using the finite element method are presented. Finally, finite element computational analysis is employed to model and simulate active vibration suppression capabilities of the ACS and ACP models employing modal, harmonic, and transient analysis. The results of modal, harmonic, and transient finite element analyses are compared for consistency. A cantilevered strut and composite beam are employed here as a fundamental study of typical structures for both axial and lateral vibration suppression to (a) develop an optimum voltage for the ACS and ACP, and (b) examine the effects of the actuator location on its ability to influence the harmonic response of the ACP structure at various modal shapes, for active lateral vibration suppression. Selected numerical results are compared with those obtained experimentally, for both ACS and ACP, and excellent results are achieved. 


\section{VERIFICATION STUDIES}

Finite element analysis (FEA) verification models, employing actuator experimental free expansions as well as analytical approaches, are presented to demonstrate the accuracy in the use of piezoelectric elements. In addition, to verify the structural dynamic analysis in the FEA numerical modeling, the natural frequencies of a structure with existing analytical solution were determined by the finite element modal analysis and compared with the analytical solution. The results of the modal analysis were also compared with the finite element harmonic analysis for consistency.

\section{Piezoelectric Verifications}

Five verification models were generated to demonstrate the accuracy in the use of piezoelectric elements for numerical modeling. All models employ a constant electric field applied to a piezoceramic actuator with various geometries. These models simulate free expansion of the actuator with a fixed boundary condition at one end to avoid rigid body motion. In the first cylindrical stack model (used for the ACS), a potential load of $+100 \mathrm{~V}$ is applied to the positive electrode along the cylinder axis to generate a displacement in the same direction, while in the flat monolithic patch models (used for the ACP) a potential load of $+100 \mathrm{~V}$ is applied to the positive electrode along the plate thickness to generate an in-plane displacement along its length. In all models, the negative electrode is grounded. The corresponding displacement of the piezo for each finite element case is determined and compared to the analytically predicted results and/or the available manufacturer experimental values to establish the validity of the FEA in the accurate use of the piezoelectric elements.

\section{PIEZOELECTRIC MODEL GEOMETRY}

For the verification models, a tubular/cylindrical stack and four flat monolithic patch piezoelectric actuators are modeled. The cylindrical stack actuator has a length of $20 \mathrm{~mm}$ and a diameter of $10 \mathrm{~mm}$. The flat monolithic patch actuators have various dimensions and will be specified later in this work. The actuators, for the verification study, are made of piezoceramic materials, PZT (lead-zirconate-titanate) with the designation of PZT-5A [41,53] and PZT-5H [53]. The stack actuator is a stack of many PZT disc wafers, and a flat patch actuator, here, is a patch of monolithic PZT flat wafers. The schematics of the piezoelectric cylindrical stack and flat monolithic patch actuators are given in Figures 1 and 2, respectively. Both the polarization and displacement directions in Figure 1 are aligned along the $z$-axis. The electrodes are placed on the two surfaces orthogonal to the 
Desired direction of displacement

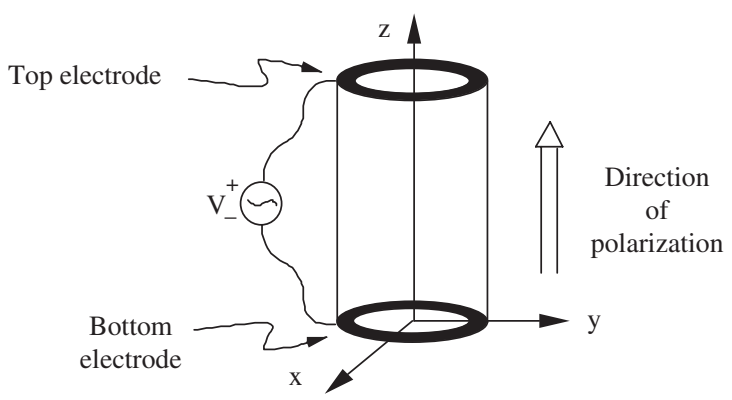

Figure 1. Schematic of a piezoelectric cylindrical stack actuator used in the ACS.

Direction of polarization (z-axis)

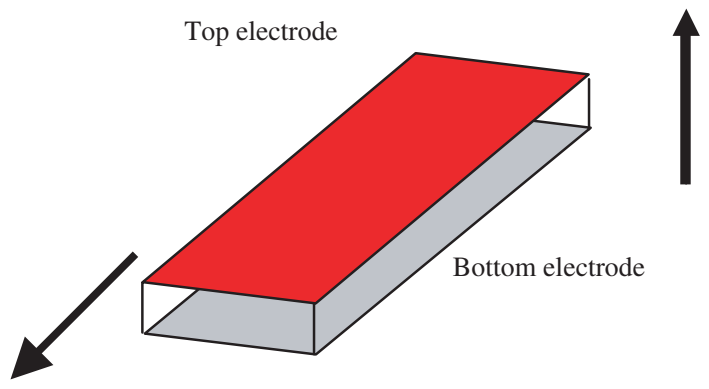

Desired direction of displacement (x-axis)

Figure 2. Schematic of a piezoelectric flat monolithic patch actuator used in the ACP.

polarization axis. In Figure 2, the polarization and desired displacement directions of the actuator are aligned along the $z$-axis and $x$-axis, respectively. The electrodes are placed on the two surfaces orthogonal to the polarization axis (i.e., $z$-axis). In Figures 1 and 2, axes $x-y$-z correspond to 1-2-3 directions as well.

\section{PIEZOELECTRIC ELEMENT TYPE}

ANSYS FEA offers piezoelectric elements [54] which allow for the coupling between the structural and electric fields in the form of SOLID5, PLANE13, and SOLID98 coupled-field elements. The SOLID5 element is a 3-D brick element with six degrees of freedom at each node, i.e., UX, UY, UZ, TEMP, VOLT, and MAG; where the value of each corresponds to the 
$x-y-z$ displacements, temperature, voltage, and scalar magnetic potential, respectively. Note that the piezoelectric effect is a dilatational effect and thus there are no rotations or shears in the material principal coordinate system. In addition, the SOLID5 element is a first-order linear element. This is acceptable for this analysis since the piezoelectric displacement field is linear for the small applied electric field.

\section{PIEZOELECTRIC MATERIAL PROPERTIES}

Piezoelectric actuators PZT-5A and PZT-5H were modeled. The material properties required by ANSYS FEA for the piezoelectric effects of the elements include the dielectric (permittivity constants) matrix [c], the elastic coefficient matrix $\left[\mathbf{c}^{\mathbf{E}}\right]$, and the piezoelectric matrix $[\mathbf{e}][19,55]$. For PZT-5A and PZT-5H, these properties are given in Equations (1) and $(2)[41,53]$.

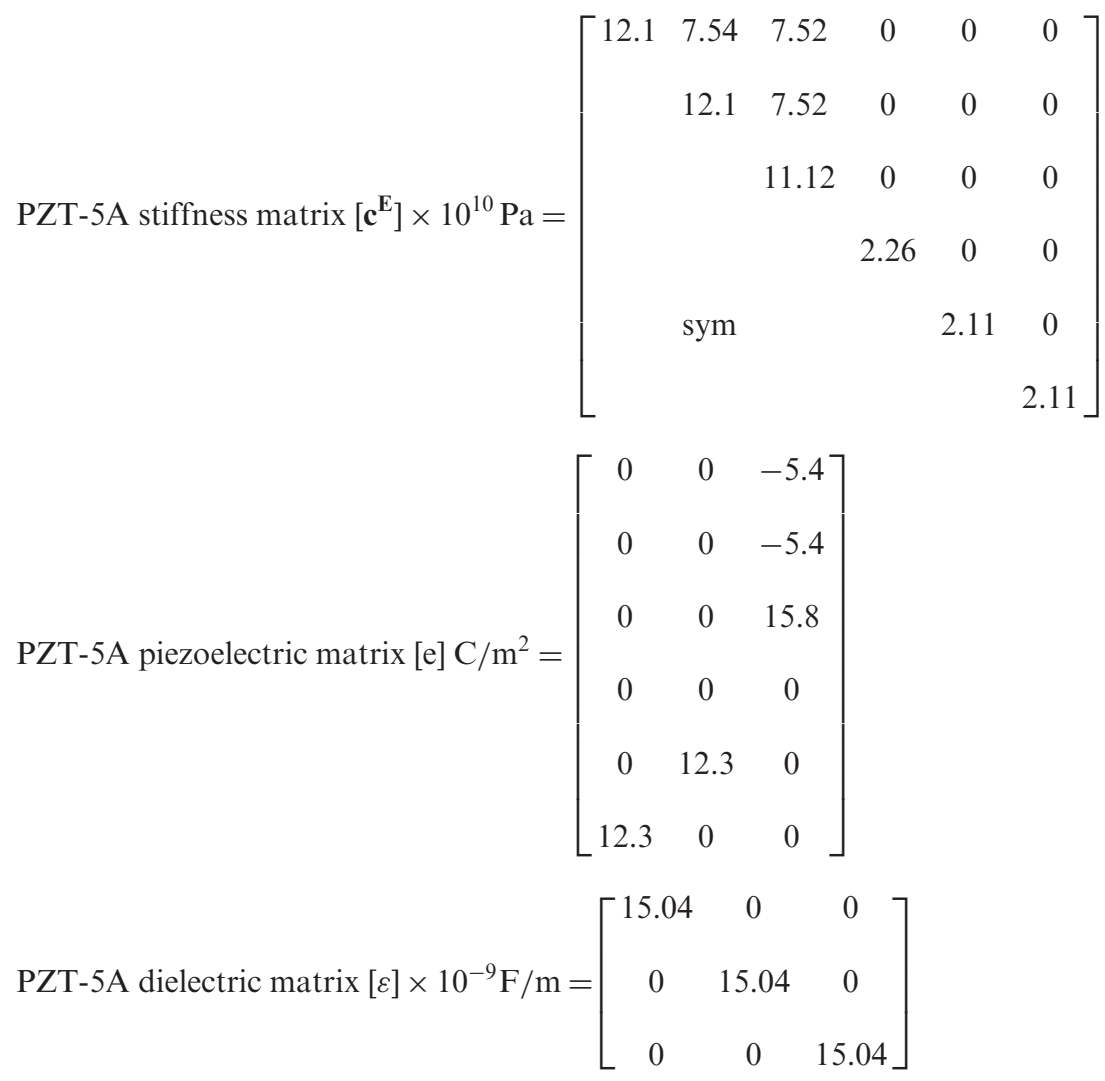


PZT-5H stiffness matrix $\left[\mathbf{c}^{\mathrm{E}}\right] \times 10^{10} \mathrm{~Pa}=\left[\begin{array}{rrrrrr}12.6 & 8.41 & 7.95 & 0 & 0 & 0 \\ & 12.6 & 7.95 & 0 & 0 & 0 \\ & & 11.7 & 0 & 0 & 0 \\ & & & 2.33 & 0 & 0 \\ & & & & 2.10 & 0 \\ & & & & & 2.10\end{array}\right]$

PZT-5H piezoelectric matrix $[\mathbf{e}] \mathrm{C} / \mathrm{m}^{2}=\left[\begin{array}{ccc}0 & 0 & -6.5 \\ 0 & 0 & -6.5 \\ 0 & 0 & 23.3 \\ 0 & 0 & 0 \\ 0 & 17.0 & 0 \\ 17.0 & 0 & 0\end{array}\right]$

PZT-5H dielectric matrix $[\varepsilon] \times 10^{-9} \mathrm{~F} / \mathrm{m}=\left[\begin{array}{ccc}15.03 & 0 & 0 \\ 0 & 15.03 & 0 \\ 0 & 0 & 13.00\end{array}\right]$

Furthermore, the piezoelectric charge coefficients, $d_{i j}[19,55]$ for PZT-5A and PZT-5H are given in Equations (3) and (4), respectively [41,53]. The density for the PZT-5A and PZT-5H are $7800 \mathrm{~kg} / \mathrm{m}^{3}$ and $7500 \mathrm{~kg} / \mathrm{m}^{3}$, respectively $[41,53]$.

PZT-5A piezoelectric charge coefficients $[\mathbf{d}]^{\mathrm{T}} \times 10^{-12} \mathrm{C} / \mathrm{N}=\left[\begin{array}{ccc}0 & 0 & -171 \\ 0 & 0 & -171 \\ 0 & 0 & 374 \\ 0 & 0 & 0 \\ 0 & 584 & 0 \\ 584 & 0 & 0\end{array}\right]$ 
PZT-5H piezoelectric charge coefficients $[\mathbf{d}]^{\mathbf{T}} \times 10^{-12} \mathrm{C} / \mathrm{N}=\left[\begin{array}{ccc}0 & 0 & -285 \\ 0 & 0 & -285 \\ 0 & 0 & 550 \\ 0 & 0 & 0 \\ 0 & 741 & 0 \\ 741 & 0 & 0\end{array}\right]$

\section{PIEZOELECTRIC BOUNDARY CONDITIONS AND LOADING}

The FEA verification models simulate free expansion of the actuators with a fixed boundary condition at one end to avoid rigid body motion. All models employ a constant electric field applied to the piezoceramic actuator along their polarization directions. In all the models, a potential load of $100 \mathrm{~V}$ is applied to the positive electrode and the negative electrode is grounded (i.e., the voltage is set equal to zero). The corresponding displacement of the piezo for each FEA case was determined and compared to the analytically predicted results as well as the available manufacturer experimental data to establish the validity of the use of the piezoelectric elements in the FEAs. Note that, in the FEA, the displacement measured is sufficiently far from the fixed boundary condition to minimize the effects of the end condition on the measured free expansion results. The end effects vanished beyond $16 \%$ of the length of the models away from the clamped end for all free expansion cases considered here.

\section{PIEZOELECTRIC VERIFICATION RESULTS}

From the literature supplied by the piezoelectric material suppliers [41,53], a piezoelectric actuator that is free to change shape and is poled along the $z$-axis (the 3-direction) will undergo free expansion in response to an applied voltage mainly in the 3-direction (i.e., $z$-axis) for the cylindrical stack of Figure 1, and mainly in the 1-direction (i.e., $x$-axis) for the flat patch of Figure 2. The displacements, $\Delta L$, are given by Equations (5) and (6) for the piezoelectric cylindrical stack and flat patch actuators, respectively [56]. Note that these equations are basically the converse (i.e., actuator) effect equations (e.g., see $[19,55])$ :

$$
\begin{aligned}
& \text { Stack : } \Delta L=d_{33} V_{\text {eff }}=d_{33} U \times n \\
& \text { Patch : } \Delta L=d_{31} V_{\text {eff }} \frac{\mathrm{L}}{\mathrm{d}}=d_{31} U \times n\left(\frac{L}{d}\right)
\end{aligned}
$$


First, consider the cylindrical/stack PZT-5A used in the ACS in this work. In Equation (5), $U$ is the actual voltage to be applied to the cylindrical stack actuator (as shown in Figure 1), $n$ is the number of wafers used within the cylindrical stack actuator, and $U \times n$ is the effective amount of the voltage,

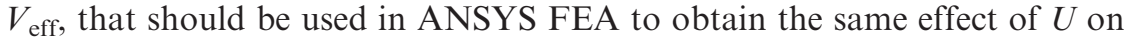
the actual piezo stack. The reason for this modeling is that in reality the piezo wafers are stacked in series mechanically but in parallel electrically. However, the way that this is modeled in ANSYS FEA is as if the wafers are stacked in series both mechanically and electrically. The following demonstrates the use of Equation (5) in ANSYS FEA and compares the FEA results with the analytical solution of Equation (5) as well as the data provided by Morgan Matroc [41] for the piezo stack actuator considered here. A piezoelectric cylindrical stack actuator was considered here with a diameter of $10 \mathrm{~mm}$ and a length of $20 \mathrm{~mm}$ [19]. According to the manufacturer data [41], this actuator extends by about $7.5 \mu \mathrm{m}$ when a constant potential of $100 \mathrm{~V}$ is applied to it [19]. The length of the piezo stack was $20,000 \mu \mathrm{m}$ and the wafer thickness within the piezo stack was $100 \mu \mathrm{m}$. Therefore, the number of the wafers within the piezo stack, $n$, was 200. Using analytical Equation (5) one can obtain Equation (7). This same model was generated in ANSYS FEA and a voltage of $U \times n=(100)$ (200) $\mathrm{V}$ was applied to the model. The resulting extension was $7.48 \mu \mathrm{m}$ (see Table 1 for results summary).

$$
\begin{aligned}
\Delta L & =d_{33} V_{\text {eff }}=d_{33} U \times n=(374 E-12 \mathrm{~m} / \mathrm{V})(100 \mathrm{~V})(200) \\
& =7.48 \mathrm{E}-06 \mathrm{~m}=7.48 \mu \mathrm{m}
\end{aligned}
$$

\section{Table 1. Numerical, analytical, and experimental displacements/strains for free expansion of piezoelectric actuators for stack and patch

\begin{tabular}{|c|c|c|c|}
\hline Piezoelectric actuators & $\begin{array}{l}\text { Numerical } \\
\text { (FEA) }\end{array}$ & $\begin{array}{c}\text { Analytical } \\
\text { Equations (5) and (6) }\end{array}$ & Experimental \\
\hline$\Delta \mathrm{L}(\mu \mathrm{m})$, PZT-5A stack, $n=200$ & 7.48 & 7.48 & 7.50 \\
\hline $\begin{array}{l}\Delta L / L(\mu \varepsilon), \text { PZT-5A patch, thin small, } \\
\quad n=1 \text { (Case I) }\end{array}$ & 134 & 134.65 & 135 \\
\hline $\begin{array}{l}\Delta L / L(\mu \varepsilon), \text { PZT- } 5 \mathrm{H} \text { patch, thin small, } \\
\quad n=1 \text { (Case II) }\end{array}$ & 224 & 224.4 & 225 \\
\hline $\begin{array}{l}\Delta L / L(\mu \varepsilon), \text { PZT- } 5 \mathrm{H} \text { patch, thick small, } \\
\quad n=2 \text { (Case III) }\end{array}$ & 224 & 224.4 & 225 \\
\hline $\begin{array}{l}\Delta L / L(\mu \varepsilon), \text { PZT- } 5 \mathrm{H} \text { patch, thick small, } \\
\quad n=1 \text { (Case IV) }\end{array}$ & 112 & 112.2 & - \\
\hline $\begin{array}{l}\Delta L / L(\mu \varepsilon), \text { PZT-5A patch, large, } \\
\quad n=1 \text { (Case V) }\end{array}$ & 67.16 & 67.32 & - \\
\hline
\end{tabular} configurations at $100 \mathrm{~V}$.}


Next, piezoelectric flat patches for both PZT-5A and PZT-5H with various geometries are considered. In Equation (6), $U$ is the actual voltage to be applied to the piezoelectric flat patch actuator (as shown in Figure 2), $n$ is the number of wafers used within the flat patch actuator, and $U \times n$ is the amount of the voltage that should be used in ANSYS FEA to obtain the same effect of $U$ on the actual piezo flat patch. The reason for this modeling is that in reality the piezo wafers are stacked in series mechanically but in parallel electrically. However, the way that this is modeled in ANSYS FEA is as if the wafers are stacked in series both mechanically and electrically. In addition, in the analytical Equation (6), $L$ and $d$ are the length and thickness of the piezoelectric flat patch actuators, repectively. It should be noted that while $L / d$ is necessary in the analytical solution, it is automatically taken care of in the ANSYS FEA. The following examples demonstrate the use of Equation (6) in ANSYS FEA and compare the FEA results with the analytical solution of Equation (6) as well as the experimental data provided by ACX [53] for the piezo flat patch actuators. Three flat geometries were considered here: first, a 'thin small' piezo flat patch with the dimensions of $(1.81$ in. $=45,974 \mu \mathrm{m}) \times(0.81 \mathrm{in} .=20,574 \mu \mathrm{m}) \times(0.005 \mathrm{in} .=127 \mu \mathrm{m})$; second, a 'thick small' piezo flat patch with the dimensions of $(1.81 \mathrm{in} .=$ $45,974 \mu \mathrm{m}) \times(0.81$ in. $=20,574 \mu \mathrm{m}) \times(0.010 \mathrm{in} .=254 \mu \mathrm{m}) ;$ third, a 'Large' piezo flat patch with the dimensions of $(2 \mathrm{in} .=50,800 \mu \mathrm{m}) \times(1.5$ in. $=38,100 \mu \mathrm{m}) \times(0.010 \mathrm{in} .=254 \mu \mathrm{m})$. Also, for some geometries, both PZT-5A and PZT 5H were considered.

\section{Case I}

In this case, the piezo is a thin small flat patch PZT-5A with $n=1$. According to the manufacturer data [53], the strain (i.e., $\Delta L / L$ ) for this actuator is $135 \mu \varepsilon$ when a constant potential of $100 \mathrm{~V}$ is applied to it. Using analytical Equation (6) one can obtain Equation (8). This same model was generated in ANSYS FEA and a voltage of $U \times n=(100)$ (1) V was applied to the model. The resulting extensional strain was $134 \mu \varepsilon$ (see Table 1 for results summary).

$$
\begin{aligned}
\frac{\Delta L}{L} & =d_{31} \frac{V_{\mathrm{eff}}}{d}=d_{31} U \times n\left(\frac{1}{d}\right)=(171 E-12 \mathrm{~m} / \mathrm{V})(100 \mathrm{~V})(1)\left(\frac{1}{127 E-06}\right) \\
& =134.65 E-06 \mathrm{~m} / \mathrm{m}=134.65 \mu \varepsilon
\end{aligned}
$$

\section{Case II}

In this case, the piezo is a thin small flat patch PZT-5H with $n=1$. According to the manufacturer data [53], the strain (i.e., $\Delta L / L$ ) for this actuator is $225 \mu \varepsilon$ when a constant potential of $100 \mathrm{~V}$ is applied to it. 
Using analytical Equation (6) one can obtain Equation (9). This same model was generated in ANSYS FEA and a voltage of $U \times n=(100)$ (1) V was applied to the model. The resulting extensional strain was $224 \mu \varepsilon$ (see Table 1 for results summary).

$$
\begin{aligned}
\frac{\Delta L}{L} & =d_{31} \frac{V_{\text {eff }}}{d}=d_{31} U \times n\left(\frac{1}{d}\right)=(285 E-12 \mathrm{~m} / \mathrm{V})(100 \mathrm{~V})(1)\left(\frac{1}{127 E-06}\right) \\
& =224.4 E-06 \mathrm{~m} / \mathrm{m}=224.4 \mu \varepsilon
\end{aligned}
$$

\section{Case III}

In this case, the piezo is a thick small flat patch PZT-5H with $n=2$. According to the manufacturer data [53], the strain (i.e., $\Delta L / L$ ) for this actuator is $225 \mu \varepsilon$ when a constant potential of $100 \mathrm{~V}$ is applied to it. Using analytical Equation (6) one can obtain Equation (10). This same model was generated in ANSYS FEA and a voltage of $U \times n=(100)$ (2) V was applied to the model. The resulting extensional strain was $224 \mu \varepsilon$ (see Table 1 for results summary).

$$
\begin{aligned}
\frac{\Delta L}{L} & =d_{31} \frac{V_{\text {eff }}}{d}=d_{31} U \times n\left(\frac{1}{d}\right)=(285 E-12 \mathrm{~m} / \mathrm{V})(100 \mathrm{~V})(2)\left(\frac{1}{254 E-06}\right) \\
& =224.4 E-06 \mathrm{~m} / \mathrm{m}=224.4 \mu \varepsilon
\end{aligned}
$$

\section{Case IV}

In this case, the piezo is a thick small flat patch PZT-5H with $n=1$. Using analytical Equation (6) one can obtain Equation (11). This same model was generated in ANSYS FEA and a voltage of $U \times n=(100)$ (1) V was applied to the model. The resulting extensional strain was $112 \mu \varepsilon$ (see Table 1 for results summary).

$$
\begin{aligned}
\frac{\Delta L}{L} & =d_{31} \frac{V_{\text {eff }}}{d}=d_{31} U \times n\left(\frac{1}{d}\right)=(285 E-12 \mathrm{~m} / \mathrm{V})(100 \mathrm{~V})(1)\left(\frac{1}{254 E-06}\right) \\
& =112.2 E-06 \mathrm{~m} / \mathrm{m}=112.2 \mu \varepsilon
\end{aligned}
$$

\section{Case V}

In this case, the piezo is a large flat patch PZT-5A with $n=1$ (the same piezoelectric flat patch actuator that is used for the ACP in this work). Using analytical Equation (6) one can obtain Equation (12). This same 
model was generated in ANSYS FEA and a voltage of $U \times n=(100)(1) \mathrm{V}$ was applied to the model. The resulting extensional strain was $67.16 \mu \varepsilon$ (see Table 1 for results summary). As shown in Table 1, the closed-form analytical, FEA numerical, and manufacturers' supplied experimental data are in excellent agreement. Table 1 shows: FEA results<analytical results $<$ experimental results (although the differences are very small, the trend is consistent).

$$
\begin{aligned}
\frac{\Delta L}{L} & =d_{31} \frac{V_{\text {eff }}}{d}=d_{31} U \times n\left(\frac{1}{d}\right)=(171 E-12 \mathrm{~m} / \mathrm{V})(100 \mathrm{~V})(1)\left(\frac{1}{254 E-06}\right) \\
& =67.32 E-06 \mathrm{~m} / \mathrm{m}=67.32 \mu \varepsilon
\end{aligned}
$$

\section{Vibration Analysis Verifications}

To verify the use of ANSYS modal and harmonic analyses, a simple solid aluminum circular rod with known analytical solution for natural frequencies was considered with a diameter of $0.0127 \mathrm{~m}(0.5 \mathrm{in}$.$) and a$ length of $0.184912 \mathrm{~m}$ (7.28 in.). Aluminum material properties used here were: $\rho=2690 \mathrm{~kg} / \mathrm{m}^{3}, E=6.9 \times 10^{10} \mathrm{~Pa}$, and $\nu=0.345$. The rod was clamped on one end. The rod fundamental axial natural frequency was found to be $6794 \mathrm{~Hz}$ analytically [57]. This rod was modeled in ANSYS FEA and its fundamental natural frequency was found to be $6823 \mathrm{~Hz}$ employing the ANSYS FEA modal analysis. The difference between the analytical and numerical solution was about $0.40 \%$. This model was also studied by ANSYS harmonic FEA and the results were practically the same. It should be mentioned that SOLID73 element was used for the aluminum cylindrical rod. This is a 3-D structural element with six degrees of freedom at each node corresponding to translations in the nodal $x$-, $y$-, and $z$-direction and rotations about the nodal $x$-, $y$-, and $z$-axis. Also, SOLID5 element was used for this aluminum rod by using aluminum properties for SOLID5. The results were the same, although SOLID5 is a more efficient element compared with SOLID73, since SOLID73 has 6 DOFs per node for this analysis as opposed to 3 DOFs per node for SOLID5, here [54]. Mesh convergence studies were performed for all FEA verification studies with a convergence criterion of less than $5 \%$.

\section{OPTIMUM VOLTAGE FOR ACTIVE VIBRATION SUPPRESSION}

The goal of this study is to demonstrate the use of FEA in determining an optimum control voltage for active vibration suppression of adaptive 
structures over a wide range of frequency encompassing a natural frequency employing (a) an active composite strut (ACS) with a piezoelectric cylindrical stack actuator for active axial vibration suppression, and (b) an active composite panel (ACP) with a surface-mounted piezoelectric flat patch actuator for active lateral vibration suppression, representing typical adaptive/intelligent structures. Numerical simulations, using modal, harmonic, and transient FEA demonstrating the vibration suppression capabilities of an active composite panel and strut have been carried out and reported in this work. A strut with cylindrical stack actuator (modeled as an ACS) with the designation of PZT-5A (same as explained in the above) is modeled in an axial vibration suppression setting. A graphite/epoxy composite cantilevered beam with a surface-mounted piezoelectric flat patch actuator (modeled as an ACP) with the designation of PZT-5A (same as Case $\mathrm{V}$ above) is modeled in a lateral vibration suppression setting. Optimum control voltages for active vibration suppression of adaptive/ intelligent structures are determined; however, no analytical control theory, based on the vibration suppression described here, has been developed in this work and is the subject of future studies. In addition, the effects of the actuator location on its ability to suppress particular mode shapes of the cantilevered composite beam, i.e., the ACP, are examined. In this study, a modal analysis was first performed to establish the first few natural frequencies of the intelligent structure. A harmonic analysis was then employed to excite a natural frequency by defining a frequency range that envelops an expected modal response. The axial and lateral displacement of the tip of the ACS telescoping rod and the composite beam were evaluated, respectively, to develop a methodology for determining the optimum actuator excitation to suppress a given mode shape. Transient FEAs were also performed and the results were in good agreement with the harmonic analyses. In addition, selected active vibration suppression experiments were performed for both the ACS axial vibration and the ACP lateral vibration, to demonstrate the validity of the numerical modeling. The numerical and experimental results were in close agreements.

\section{Optimum Voltage for the ACS Axial Vibration Suppression using FEA}

Figure 3 shows the schematic of the modeled internal components of an ACS [19], where the shown system is placed inside a composite housing with proper bearings and clamps [19]. For the active vibration suppression capability of the ACS, the left block (Lb) in Figure 3 is clamped, the right block ( $\mathrm{Lb})$ is free, the right rod ( $\mathrm{Lr}$ ) passes through a bearing, and the external axial vibration is imposed on the strut through its right telescoping 


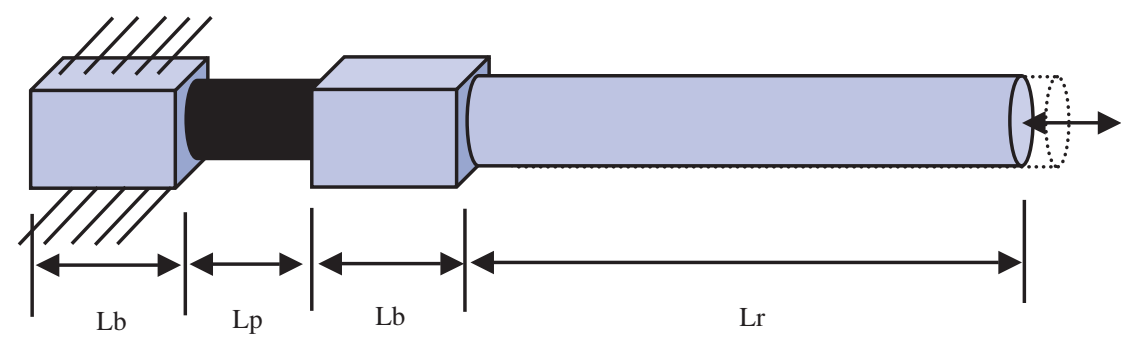

Block width $=0.014224 \mathrm{~m}$
Block height $=0.014224 \mathrm{~m}$
Dp $=0.0100 \mathrm{~m}$
Dr $=0.0127 \mathrm{~m}$

$\mathrm{Lb}=0.018923 \mathrm{~m}$
$\mathrm{Lp}=0.020000 \mathrm{~m}$
$\mathrm{Lr}=0.127 \mathrm{~m}$
$\mathrm{~b}=$ block, $\mathrm{p}=$ piezo, $\mathrm{r}=\operatorname{rod}$

Figure 3. Schematic of the ACS finite element model with piezoelectric cylindrical stack actuator for axial vibration [19].

rod (i.e., Lr in Figure 3). The material properties for the piezoelectric stack PZT-5A and the aluminum were given earlier in this work. The ANSYS FEA result of Figure 3 model employing a modal analysis for Mode I axial vibration provided a natural frequency of $7,386 \mathrm{~Hz}$. Mode II for this system was at $22,043 \mathrm{~Hz}$. SOLID5 element was used for both piezoelectric and aluminum parts with their respective properties. The use of SOLID73 for the aluminum yields the same results.

In an active vibration suppression, the vibration of the structure is determined first (analytically/numerically and/or experimentally using sensors), then actuators are exited to generate a vibration internally with the same frequency but $180^{\circ}$ out-of-phase with the imposed external vibration (which is a reasonable assumption for structures with low structural damping such as those used in here) to partially or entirely suppress the imposed vibration depending upon the amount of the applied actuator voltage and phase difference. Figure 4 shows the results of the harmonic analysis for Mode I for the active axial vibration suppression of the strut when actuating the piezo stack employing actuator peak voltages ranging from 0 to $20 \mathrm{~V}$, where $0 \mathrm{~V}$ corresponds to external excitation only with no internal actuator excitation. The piezoelectric and aluminum properties were those given earlier in this work. It was assumed that a harmonic pressure of $350 \mathrm{kPa}$ (corresponding to about $44.5 \mathrm{~N}$ or $10 \mathrm{lbs}$ ) was applied axially at the end of the telescoping rod. Figure 4 shows that the optimum actuator peak voltage for active vibration suppression may vary at different frequencies and may not always be a 'constant' value over a wide range of frequency. In Figure 4, the peak displacements identify the natural frequency of the system. Figure 4 shows a slight shift of the peak of the system to the left when the piezoelectric stack is actuated simultaneously 


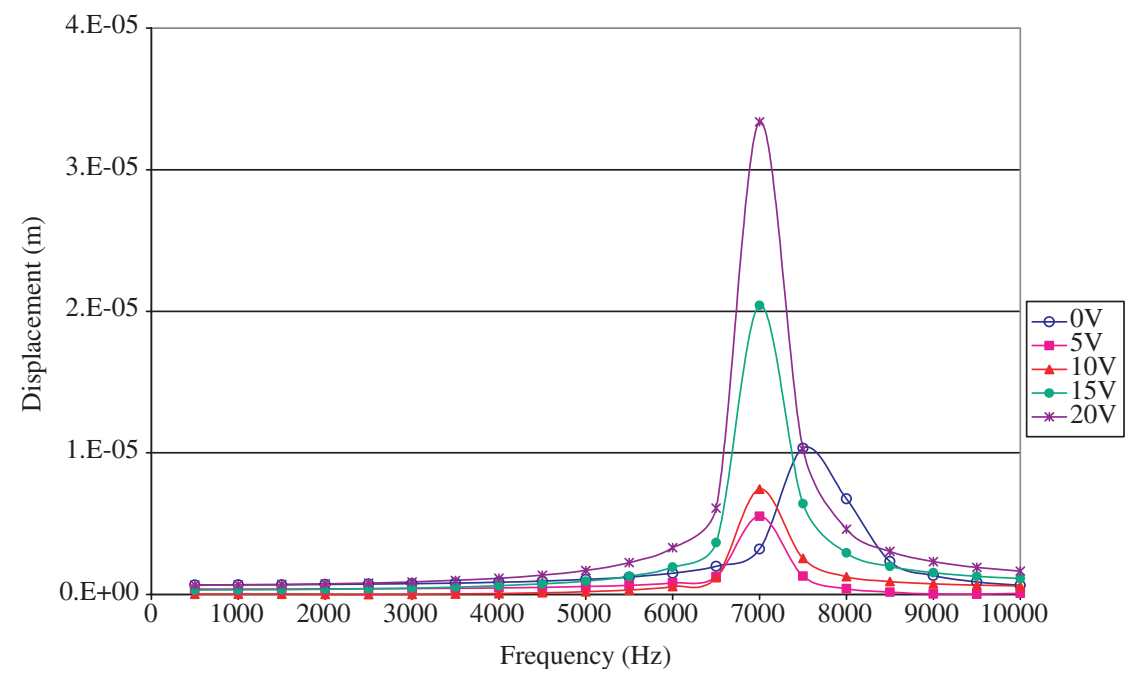

Figure 4. Active axial vibration suppression of the ACS employing finite element harmonic analyses with various actuator 'constant' peak voltages over a frequency range around the first mode, $7386 \mathrm{~Hz}$.

with the external load. This difference, however, decreases with the frequency increment refinement and approaches that of the $0 \mathrm{~V}$ case, which is consistent with the modal analysis result. As a result, the information around the natural frequency for a coarse frequency mesh is not as accurate as the information away from it, here. To examine the behavior shown in Figure 4 closer, a range of $0-2000 \mathrm{~Hz}$ of Figure 4, i.e., a practical frequency range of interest for a satellite thrust vector control (TVC) application [19,43], which also happens to be much less than the ACS first natural frequency here, was considered and is shown in Figure 5. Figure 5 shows that as the actuator peak voltage increases from 0 to $10 \mathrm{~V}$, the maximum displacement in harmonic analysis decreases to its minimum value. It should be noted that the vibration generated by the actuator at each frequency has the same frequency of the structure but is $180^{\circ}$ out-of-phase (which is even a more reasonable assumption away from the natural frequency) to actively suppress the vibration. This suppression reaches its maximum value at $10 \mathrm{~V}$ actuator peak voltage. Beyond $10 \mathrm{~V}$, the actuator excites the structure $180^{\circ}$ out-of-phase more than needed, and hence increases the vibration amplitude compared to the $10 \mathrm{~V}$ optimum voltage case, $180^{\circ}$ out-of-phase in the negative direction in Figure 5; however, their absolute values are shown here to compare the vibration magnitudes of $0-10 \mathrm{~V}$ with those of $10-20 \mathrm{~V}$. This phenomenon is examined more in details employing a transient analysis. Figures 6 and 7 show typical pressure-time 


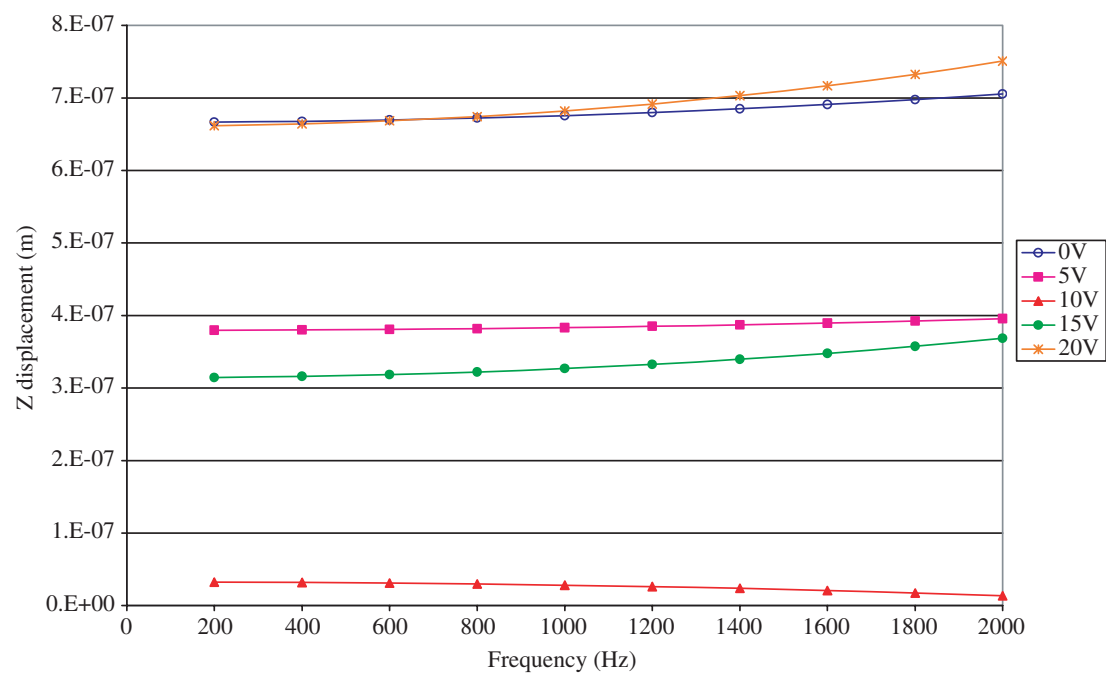

Figure 5. Active axial vibration suppression of the ACS employing finite element harmonic analyses and various actuator peak voltages for $0-2000 \mathrm{~Hz}$.

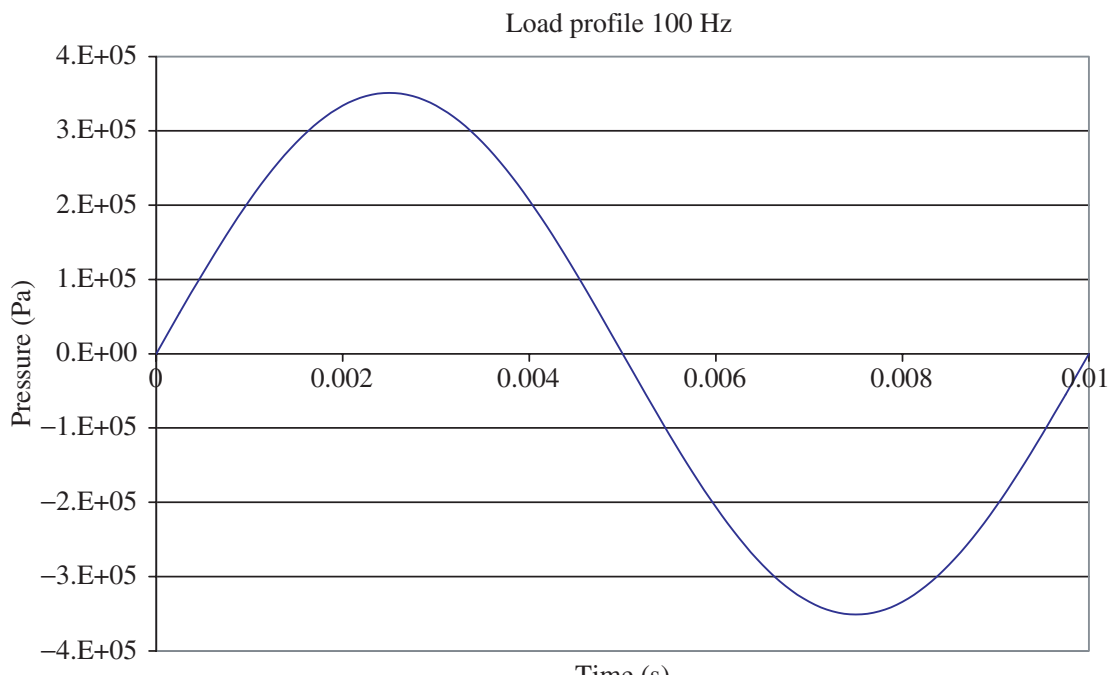

Time (s)

Figure 6. A typical pressure-time curve used in the ACS transient analyses.

(for the external force) and voltage-time (for the actuator as the internal force) curves, respectively, used in the transient analysis of Figure 8 for $100 \mathrm{~Hz}$. Figures 6 and 7 depict the peak external pressure of $350 \mathrm{kPa}$ and optimum peak voltage of $10 \mathrm{~V}$, respectively, used in Figure 8. Figures 8 and 


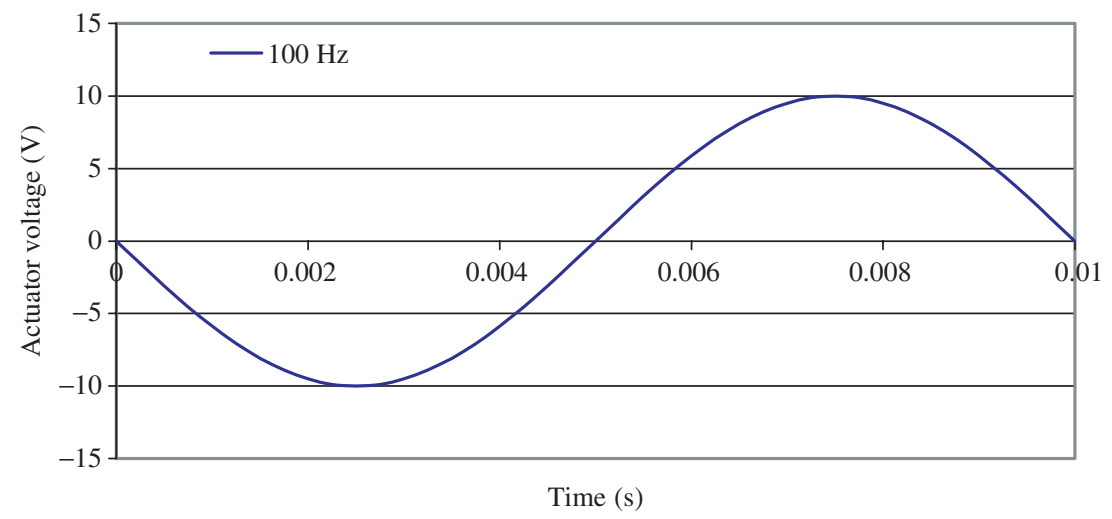

Figure 7. A typical actuator voltage-time curve used in the ACS transient analyses.

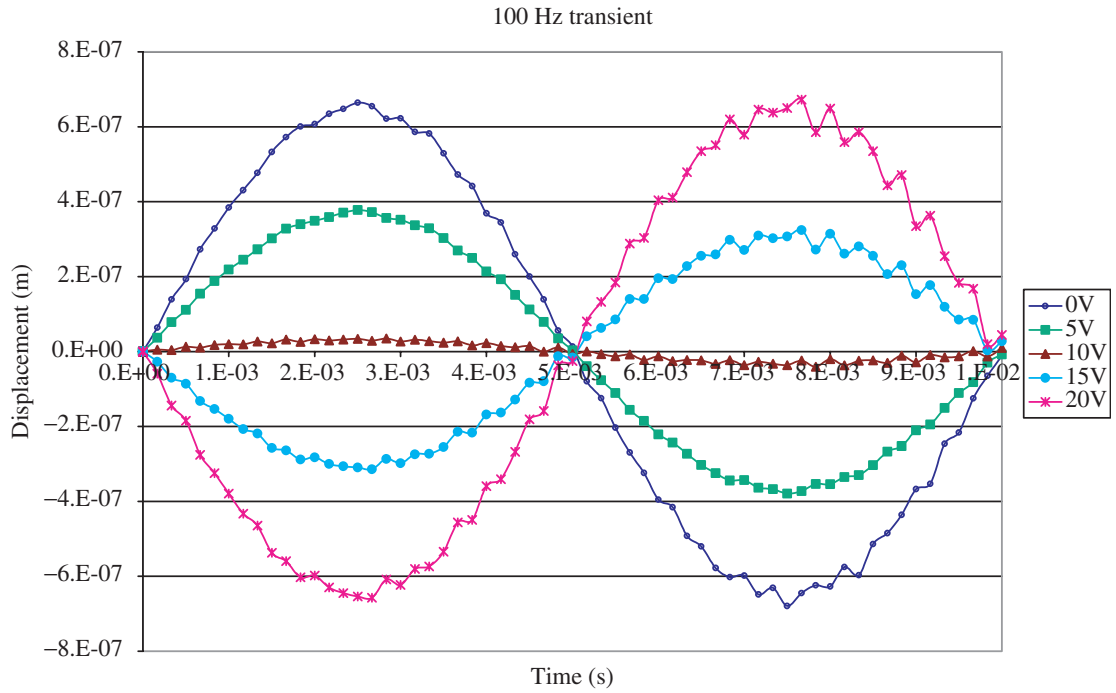

Figure 8. Active axial vibration suppression of the ACS employing finite element transient analyses and various actuator peak voltages at $100 \mathrm{~Hz}$.

9 show two of the typical transient analyses performed at $100 \mathrm{~Hz}$ and $1000 \mathrm{~Hz}$, respectively. The pressure-time curve for the analysis of Figure 9 has the same shape as in Figure 6 except for the time-axis that changes from the range of $0-0.01 \mathrm{~s}$, for $100 \mathrm{~Hz}$ analysis, to $0-0.001 \mathrm{~s}$, for the $1000 \mathrm{~Hz}$ analysis, and likewise for the voltage-time curve. Consistent with the harmonic analysis, transient analysis also shows that as the actuator peak voltage increases from 0 to $10 \mathrm{~V}$, the displacement in transient analysis 


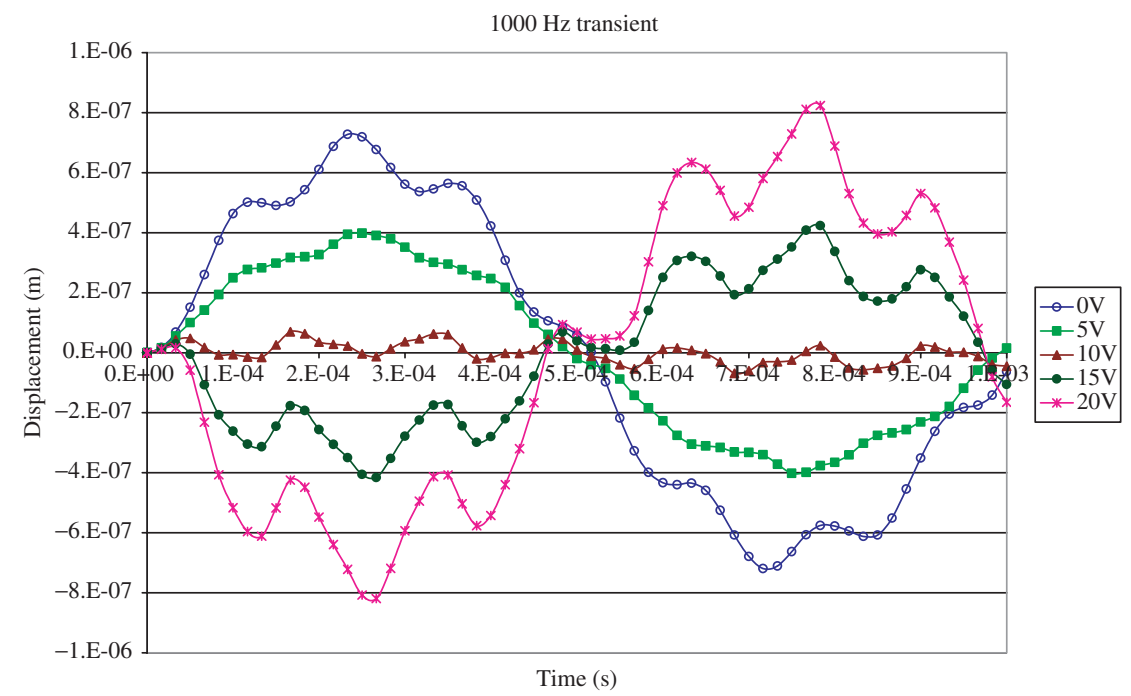

Figure 9. Active axial vibration suppression of the ACS employing finite element transient analyses and various actuator peak voltages at $1000 \mathrm{~Hz}$.

decreases to its minimum value. The vibration generated by the actuator at each frequency has the same frequency of the structure but is $180^{\circ}$ out-ofphase to actively suppress the vibration. This suppression reaches its maximum value at $10 \mathrm{~V}$ 'actuator peak voltage,' henceforth is, briefly, referred to as 'actuator voltage.' Beyond the $10 \mathrm{~V}$, the actuator excites the structure $180^{\circ}$ out-of-phase more than needed, and hence increases the vibration amplitude compared to the $10 \mathrm{~V}$ optimum/threshold voltage level. It should be noted that the $20 \mathrm{~V}$ case, i.e., double of that of the actuator optimum/threshold voltage, will take the vibration amplitude back to the level of zero actuator voltage, in the opposite direction (Figures 5, 8, and 9). A similar trend exits at other frequencies using the transient analysis, and all were consistent with the harmonic analysis. Also, a linear relationship exits between the level of applied force and the required optimum/threshold voltage between $0-44.5 \mathrm{~N}(0-10 \mathrm{lbs})$, which produced a $0-10 \mathrm{~V}$ actuator optimum/threshold voltage. Furthermore, it is observed in the transient analysis that when the applied frequency approaches the natural frequency, the amplitude of the waviness of the transient response increases (see Figures 8 and 9 , and is more accentuated for $0 \mathrm{~V}$ and $20 \mathrm{~V}$ responses), but the frequency of this waviness will always add up to about the natural frequency (i.e., $7386 \mathrm{~Hz}$, in this case) regardless of the external applied load frequency. This is believed to be due to the transient effects of the transient response. 


\section{Optimum Voltage for the ACS Axial Vibration Suppression using Experiments}

Figure 3 is the FEA model of the ACS axial vibration test setup given in Figure 10 schematically. The actual test set up of Figure 10 is given in Figure 11. The left block is clamped, the right block is unclamped, and the axial external vibration is applied on the strut through its telescoping rod [19] using a shaker. The vibration is sensed by a fiber optic sensor setup. The shaker was supplied with $100 \mathrm{~Hz}$ frequency and $0.1 \mathrm{~V}$ amplitude through an amplifier. An amplifier was employed to change the output voltage, and consequently the amplitude of the shaker. Using an amplifier was necessary to reach the required magnitude of the amplitude. The shaker was mounted

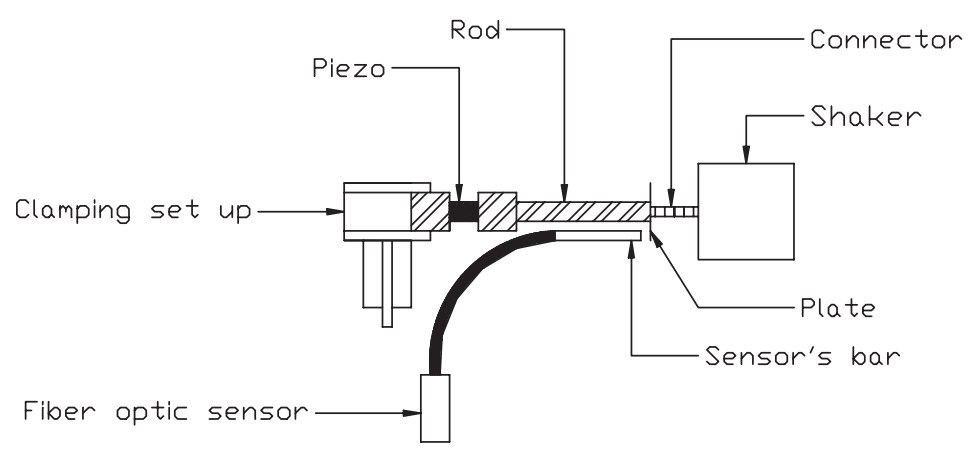

Figure 10. Schematic of the ACS active axial vibration suppression test setup.

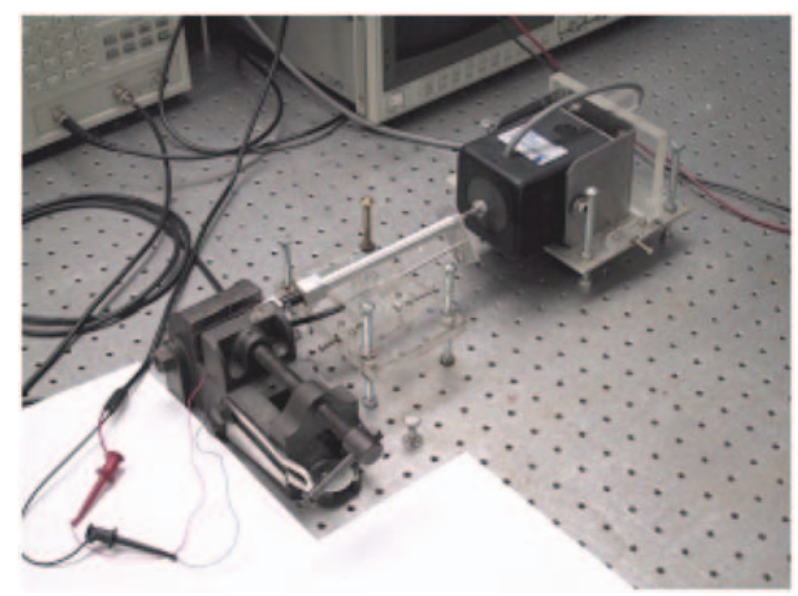

Figure 11. ACS active axial vibration suppression test setup. 
on a rigid hard plastic housing and was clamped onto a vibration isolation table (Figure 11). The shaker was leveled and its connection to the ACS telescoping rod was provided by a screw that was attached to the shaker vibrating point at one end and to the ACS telescoping rod at the other end. A rigid aluminum plate was mounted at the end of the ACS telescoping rod to help measure the rod displacement. In fact, this sensor plate movement was the displacement that was measured by a fiber optic sensor. The efficiency of the fiber optic sensor was $0.1 \mathrm{mV}$. The fiber optic sensor bar was mounted on a rigid and level hard plastic plate near the sensor plate at the end of the ACS telescoping rod. The fiber optic sensor bar was placed in contact with the sensor plate, which was attached to the end of the ACS telescoping rod to avoid any noise that could affect the efficiency of the sensor. A power supply, for the sensor, generated $20 \mathrm{~V}$ output to activate the sensor. The measurement of the sensor was transformed to a dynamic signal analyzer to investigate the results. To clamp the end of the sample, a set up consisting of a vise and a supporter was used to constrain any displacement at the clamped end of the sample. The sample was perpendicular to the sensor plate at the end of the ACS telescoping rod and in a straight line with the shaker movement. This setup is shown in Figure 11. Since the displacement of an excited piezoelectric stack was in terms of microns the applied voltage to the shaker was adjusted to generate vibrations with amplitudes in the range of the stack displacement. First, the shaker was considered to be the only source of the vibration applied to the system. To investigate the effects of the shaker and piezo on the system the magnitude of the system displacement was measured. To measure system displacement, the displacement of the sensor plate, attached at the end of the ACS telescoping rod, was transformed to an analysis digitizer via a fiber optic sensor. Figure 12 shows the sinusoidal graph of the axial vibration of the ACS telescoping rod imposed by the shaker at $100 \mathrm{~Hz}$, which is the result of the transformed displacement data to the analysis digitizer. The measured pick-to-pick displacement was $4 \mathrm{mV}$. Next, the shaker was turned off and only the piezoelectric stack was actuated at $100 \mathrm{~Hz}$. The amplitude of the applied sinusoidal voltage, generated by a function generator, was $40 \mathrm{~V}$ and was obtained experimentally, similar to the constant optimum voltage determination in the analysis section presented in Figure 5, where the type of the applied current was AC in mil-amps. Similar to the shaker displacement measurement, the fiber optic sensor transformed a converted current due to the shaft displacement to a dynamic analyzer. The pick-to-pick displacement measured was $4 \mathrm{mV}$ and the graph was similar to Figure 12, but $180^{\circ}$ out-ofphase. Finally, the shaker and the piezoelectric stack were excited at the same time. To obtain the vibration suppression results, the input sinusoidal voltage to the shaker and piezo stack should be at the same frequency but 


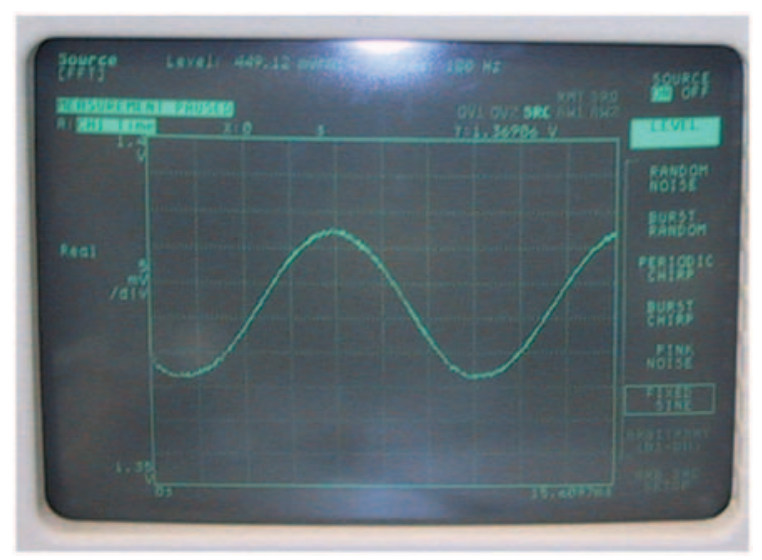

Figure 12. Dynamic analyzer displacement-time graph based on the shaker sinusoidal input.

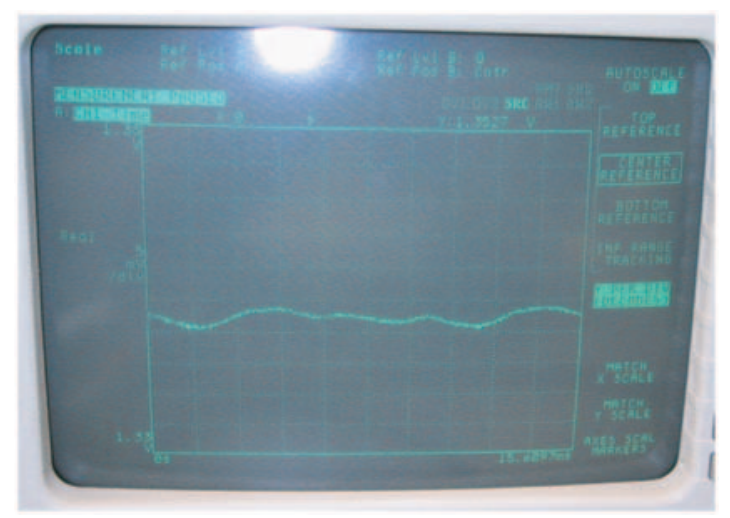

Figure 13. Dynamic analyzer displacement-time graph showing an active vibration suppression while shaker and piezoelectric are actuated, $100 \mathrm{~Hz}, 180^{\circ}$ out-of-phase.

$180^{\circ}$ out-of-phase, and were obtained by function generators for this experiment. The active vibration suppression result for this case is shown in Figure 13, where the pick-to-pick displacement measured is $0.8 \mathrm{mV}$. It should be mentioned that Figures 12 and 13 use the same scales. As a result, the vibration imposed by the shaker has been actively suppressed by the piezoelectric stack by $80 \%$. Based on the linear relationship of the applied axial load versus the constant optimum voltage value obtained in the numerical analysis earlier, a voltage value of $40 \mathrm{~V}$ corresponds to $178 \mathrm{~N}$ (40 lbs) applied axial load. It should be noted that the left block in this experiment was placed inside a vice that could take loads much higher than 
the actual ACS clamping system [19]. Therefore, the experiment was repeated for two more lower load levels (produced by the shaker) to give pick-to-pick displacements of 1 and $0.5 \mathrm{mV}$ (with either the shaker alone or the actuator alone), which resulted in actuator voltages of 10 and $5 \mathrm{~V}$ corresponding to 44.5 and $22.25 \mathrm{~N}$ (10 and 5lbs) applied shaker loads, respectively. During these tests, graphs similar to Figures 12 and 13 were obtained and the degree of the vibration suppression was about $80-90 \%$. It should be noted that the experimental case of applied shaker load of $44.5 \mathrm{~N}$ $(10 \mathrm{lbs})$ resulting in the control voltage of $10 \mathrm{~V}$ is similar to the finite element results obtained by the optimum voltage vibration suppression scheme shown in Figure 5. As a result, an excellent agreement is achieved between the numerical and experimental results for the ACS axial vibration suppression study.

\section{Optimum Voltage for the ACP Lateral Vibration Suppression using FEA}

Figure 14 shows the FEA solid model used for the active composite panel (ACP). The vibration suppression model consists of a cantilevered graphite/ epoxy composite beam $15.24 \mathrm{~cm}(6 \mathrm{in}$.) in length, $3.81 \mathrm{~cm}(1.5 \mathrm{in}$.$) in width,$ and $1 \mathrm{~mm}(0.040 \mathrm{in}$.) in thickness with a $5.08 \mathrm{~cm}$ ( 2 in.) long, $3.81 \mathrm{~cm}(1.5 \mathrm{in}$.) wide, and $0.254 \mathrm{~mm}(0.010 \mathrm{in}$.) thick piezoelectric patch actuator located at the center/midpoint of the beam. The polarization direction of the actuator is aligned along its $z$-axis (Figure 2) and is mounted in such a way that the $z$-axis (3-direction) of the actuator corresponds to the $z$-axis (3-direction) of the composite beam (Figure 14). The electrodes are on the two surfaces, which are orthogonal to the polarization axis (Figure 2). The piezoelectric actuator main extension/contraction is in its length that is along the $x$-axis (i.e., 1-direction). In Figure 14, the length, width, and thickness directions are $x=1, y=2$, and $z=3$ axes, respectively.

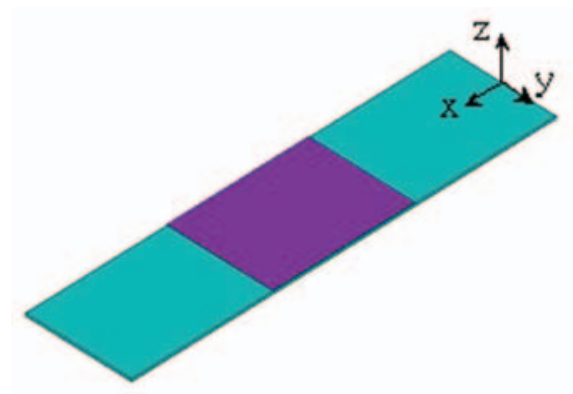

Figure 14. FEA solid model of the active composite panel (ACP) with piezoelectric flat patch actuator at the beam center. 
As in the verification model presented in the previous sections, the SOLID5 element was used to model the piezoelectric effect. This coupled field element has six degrees of freedom at each node corresponding to three translations along with temperature, voltage, and scalar magnetic potentials, and can accept anisotropic/orthotropic properties. The SOLID5 was also used for the composite beam where the composite properties were input for SOLID5. The SOLID73 element was also used to model the composite beam to compare its results with SOLID5 used for the composite beam. This 3-D structural element can be used to model orthotropic behavior of materials, and similar results were obtained using SOLID5 or SOLID73 for the composite beam, although SOLID5 is a more efficient element (in terms of lower DOFs per node) than SOLID73.

The material chosen for the piezoelectric actuator is the same as the one used in the verification models, i.e., PZT-5A and was manufactured by Morgan Matroc, Inc. [41]. To model the piezoelectric behavior, ANSYS FEA requires the dielectric matrix, elastic coefficient matrix, and the piezoelectric matrix, all of which were defined earlier. The piezoelectric material properties for PZT-5A used in this section and required by ANSYS FEA are given in the previous sections.

The composite beam is modeled as T300 graphite plain weave cloth, designated by $(0 / 90)$ for a woven ply, impregnated with Fiberites 934 epoxy resin. The laminate is a symmetric layup and is designated as $(0 / 90)_{4 \mathrm{~s}}$, which indicates overall eight plies of woven cloth. The individual ply thickness is $0.127 \mathrm{~mm}(0.005 \mathrm{in}$.), which results in an overall laminated thickness of $1 \mathrm{~mm}$ ( $0.040 \mathrm{in}$.). The values of the Young's and shear moduli in three material directions as well as Poisson's ratios for the laminate were determined using composite woven materials effective properties modeling [58] and are given in Equation (13) along with the composite density.

$$
\begin{aligned}
E_{x} & =7.75 \times 10^{10} \mathrm{~N} / \mathrm{m}^{2} \quad G_{x y}=5.86 \times 10^{9} \mathrm{~N} / \mathrm{m}^{2} \\
E_{y} & =7.75 \times 10^{10} \mathrm{~N} / \mathrm{m}^{2} \quad G_{y z}=4.66 \times 10^{9} \mathrm{~N} / \mathrm{m}^{2} \\
E_{z} & =1.13 \times 10^{10} \mathrm{~N} / \mathrm{m}^{2} \quad G_{x z}=4.66 \times 10^{9} \mathrm{~N} / \mathrm{m}^{2} \\
v_{x y} & =0.03 \quad v_{y z}=0.30 \\
v_{x z} & =0.30 \quad \rho=1578 \mathrm{~kg} / \mathrm{m}^{3}
\end{aligned}
$$

The vibration model consists of a composite cantilevered beam (i.e., fixed at one end, $x=0$, and free at the other end, see Figure 14) with a single surface-mounted piezoelectric flat patch, PZT-5A, actuator. Since the piezoelectric actuator is bonded onto the surface of the composite beam, 
the two are under mutual constraint to displace together to maintain displacement compatibility at the bonded interface. Therefore, a voltage potential applied to the actuator will result in the displacement of the beam. If the voltage potential is harmonic, then the piezo will generate a harmonic vibration response in the beam. To actively suppress the vibration, the internal vibration generated by the piezo should be at the same frequency but $180^{\circ}$ out-of-phase with the imposed external vibration (once again, this is a reasonable assumption since the structural damping is low in here). The level of suppression depends on the amount of the actuator voltage and the accuracy of the phase difference.

First, a modal analysis of the composite cantilevered beam with a surfacemounted piezoelectric actuator was performed to establish the first four natural frequencies of the system. Figures 15 through 35 show the first four mode shapes and their active vibration suppression. The first natural frequency occurs at $46.34 \mathrm{~Hz}$ and is the first cantilever bending mode. Likewise, the second through fourth frequencies occur at 298.23, 832.42, and $1763 \mathrm{~Hz}$, respectively, and are higher bending modes of the composite cantilevered beam as are evident from the mode shapes. Then, for each natural frequency, a harmonic analysis was performed to excite the natural

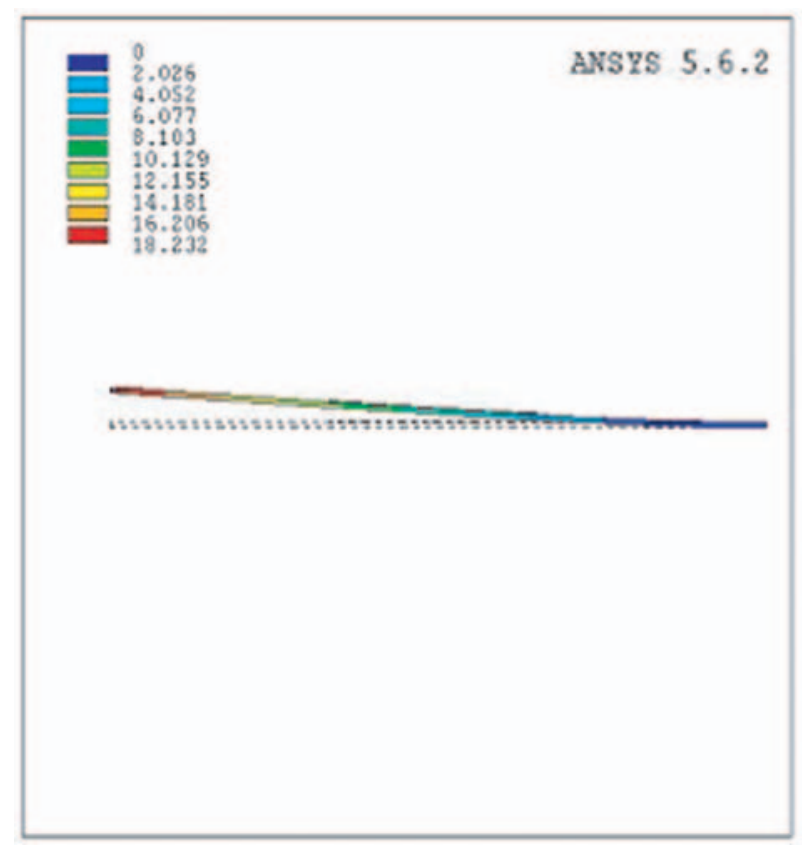

Figure 15. ACP Mode I, $46.34 \mathrm{~Hz}$, modal analysis. 
frequency by defining a frequency range that envelops the modal response under consideration. Each frequency range is divided into a number of frequency intervals to generate sufficient data points. The output amplitude and phase of the displacement at the tip of the beam (i.e., the location of interest) were tabulated. Based on these results, various harmonic voltage values, starting with low values, were applied to the piezoelectric actuator at all frequencies with the same frequency of the structure but $180^{\circ}$ out-of-phase to suppress the beam tip vibration. Next, the level of the voltage was increased and the beam tip displacement was recorded. This procedure was repeated till the displacements caused by the piezoelectric actuator overcame the external disturbance and beyond an optimum/ threshold voltage, the piezoelectric actuator started to increase the vibration displacement in the opposite direction (i.e., $180^{\circ}$ out-of-phase), and as the voltage value further increased the level of the structural vibration amplitude increased in the opposite direction. This increase in the structural vibration amplitude in the opposite phase/direction is shown, in this work, in the same phase/direction for the harmonic analyses, but the opposite phase/direction in the transient analyses, for clarity. Therefore, for each natural frequency, the optimum/threshold voltage is first determined by the finite element harmonic analysis over a range of the frequency that envelops the natural frequency under consideration, then this level of optimum voltage is also evaluated at selected frequencies by an equivalent finite element transient analysis, to verify the optimum voltage (OV) numerically.

\section{ACP LATERAL VIBRATION SUPPRESSION FEA RESULTS AND DISCUSSIONS}

The effectiveness of the optimum voltage active vibration suppression was evaluated for the composite cantilevered beam model of Figure 14. Figure 15 shows the mode shape of the first natural frequency, Mode I, at $46.34 \mathrm{~Hz}$. Henceforth, the term 'uncontrolled' means that only the external load is being applied to the structure and the actuator voltage is $0 \mathrm{~V}$. On the other hand, the term 'controlled' means that in addition to the external load, internal load supplied by a non-zero actuator voltage also exists, simultaneously. Figure 16 shows displacement responses of the composite beam tip, for various actuator voltages. It is found that around the natural frequency, the optimum voltage $(\mathrm{OV})$ is about $280 \mathrm{~V}$. A closer examination of this figure reveals that the OV at different frequencies has different values. Figure 17 demonstrates that the level of vibration suppression for an actuator voltage is different at various frequencies, and hence the $\mathrm{OV}$ is different for different frequencies. It should be mentioned that for some ranges of frequencies the OV may remain constant, e.g., see Mode II of ACP or Mode I of ACS (shown in Figure 4 where the OV is $10 \mathrm{~V}$ 


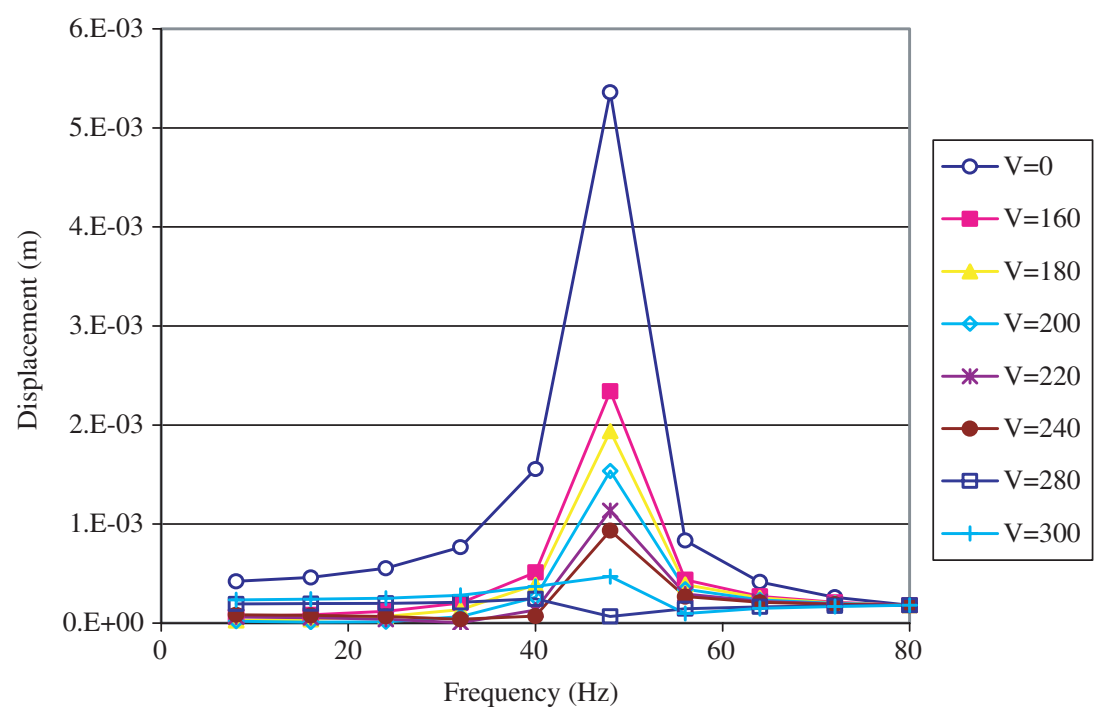

Figure 16. Vibration suppression of ACP Mode I, $46.34 \mathrm{~Hz}$, harmonic analysis for $0-80 \mathrm{~Hz}$.

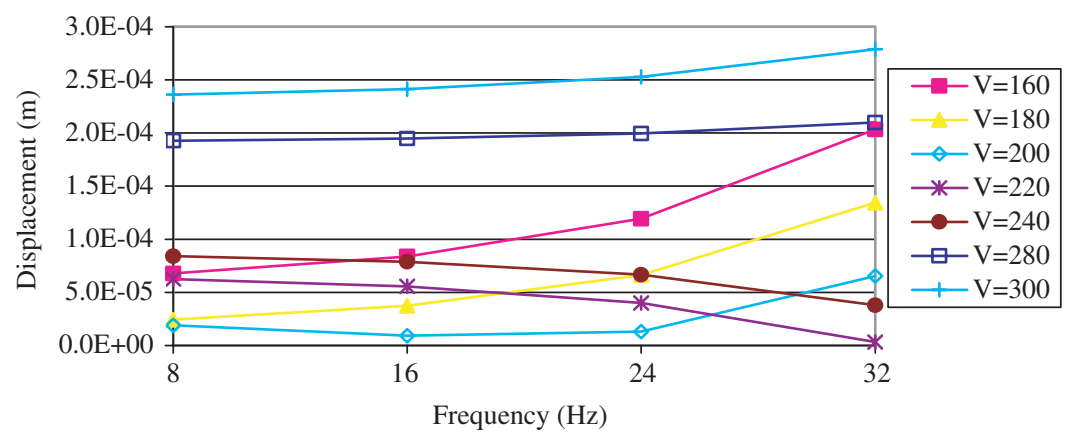

Figure 17. Vibration suppression of ACP Mode I, $46.34 \mathrm{~Hz}$, harmonic analysis for $8-32 \mathrm{~Hz}$.

for the axial harmonic load, with $44.5 \mathrm{~N}$ or $10 \mathrm{lbs}$ in peak, for a range of $0-6000 \mathrm{~Hz}$ with the fundamental axial natural frequency of $7386 \mathrm{~Hz}$ ). Also, the level of OV is obviously a function of the external applied load but for this study the level of the peak of the lateral harmonic applied load was maintained fixed at $0.1 \mathrm{~N}$ at the ACP tip for the demonstration purpose. A peak in Figure 16 roughly indicates the system Mode I natural frequency, the accuracy of which for the harmonic analysis depends on the frequency step size. 
To further examine this phenomenon, transient analyses were performed at the 16 and $32 \mathrm{~Hz}$ of Figures 16 and 17, to demonstrate the consistency of this phenomenon in both harmonic and transient analyses. Figure 18 shows a typical lateral total harmonic line force applied to the tip of the composite beam with a peak of $0.1 \mathrm{~N}$ at $32 \mathrm{~Hz}$. Figure 19 shows a typical harmonic actuator voltage with a peak of $50 \mathrm{~V}$ at $32 \mathrm{~Hz}$. Once again, an actuator voltage of $50 \mathrm{~V}$, throughout this work, means a harmonic voltage similar to Figure 19 where the peak voltage is $50 \mathrm{~V}$ (as internal load), and likewise for the external load/force. The results of transient analyses for 16 and $32 \mathrm{~Hz}$ of Figures 16 and 17 are given in Figures 20 and 21.

Figures 16 and 17 show that, e.g., at $16 \mathrm{~Hz}$ the vibration amplitude decreases for actuator voltages of 160,180 , and $200 \mathrm{~V}$, and then beyond $200 \mathrm{~V}$ the actuator starts increasing the vibration $180^{\circ}$ out-of-phase with the

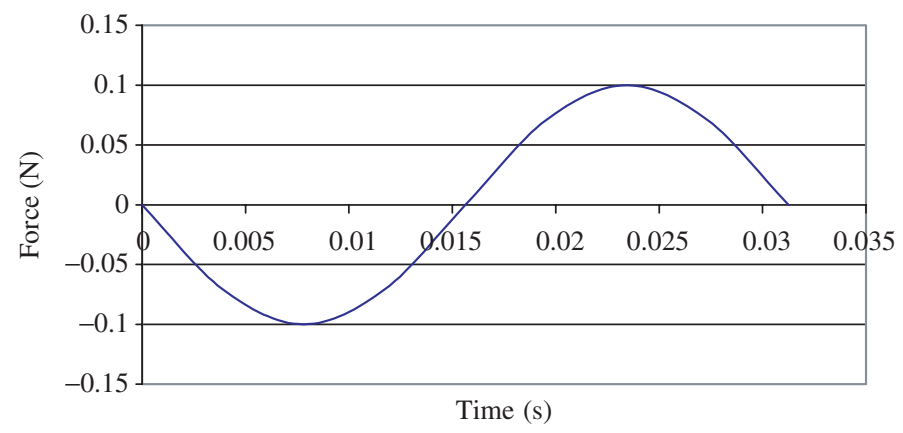

Figure 18. A typical lateral load-time curve at $32 \mathrm{~Hz}$ used in ACP transient analyses.

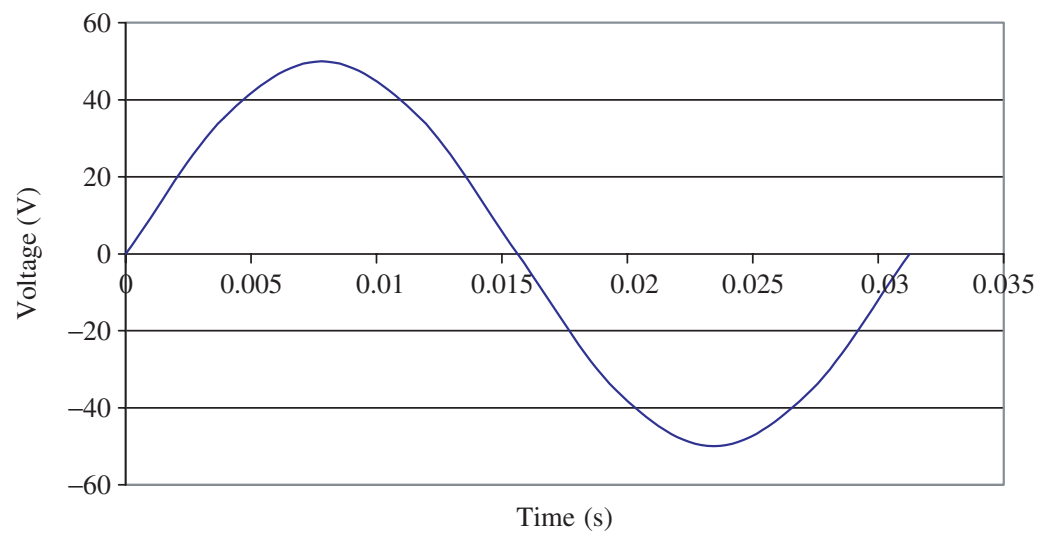

Figure 19. A typical voltage-time curve at $32 \mathrm{~Hz}$ used in ACP transient analyses. 


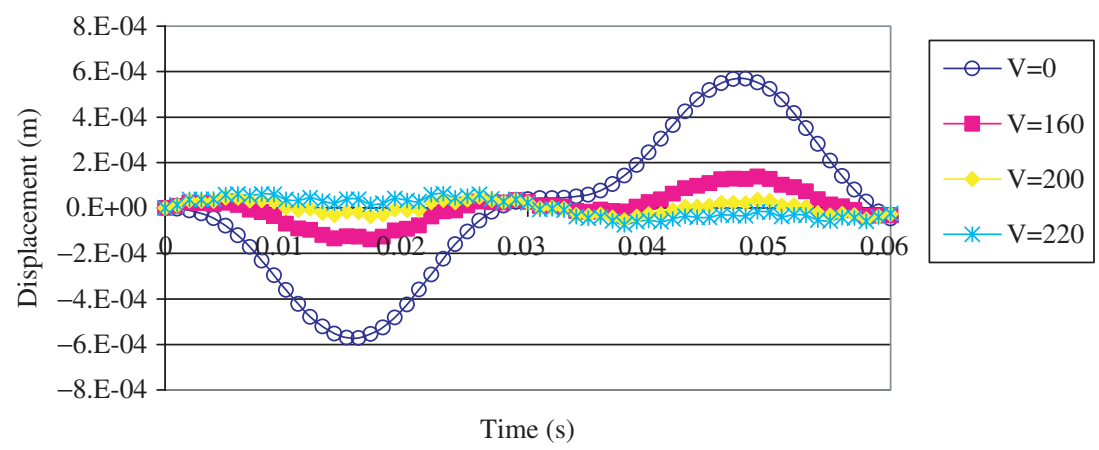

Figure 20. Transient analysis of Figures 16 and 17 at $16 \mathrm{~Hz}$ for ACP.

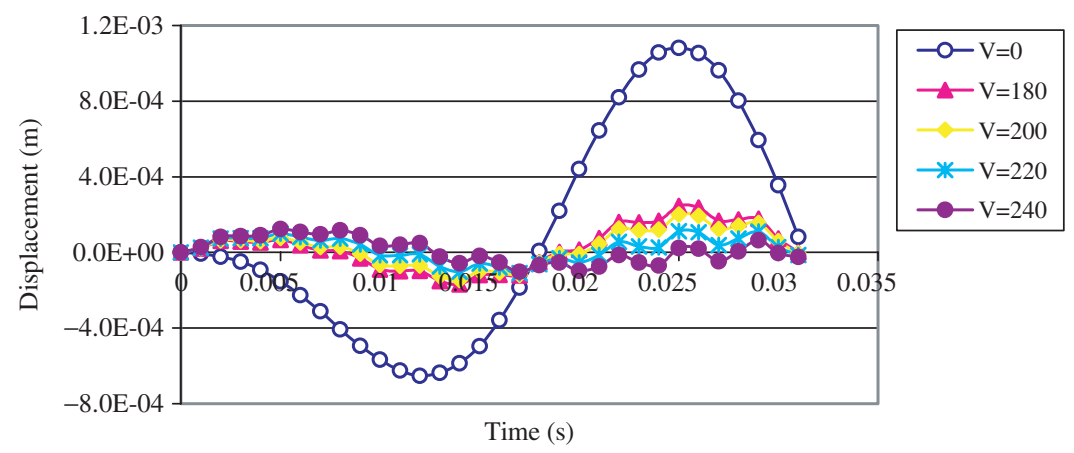

Figure 21. Transient analysis of Figures 16 and 17 at $32 \mathrm{~Hz}$ for ACP.

structural vibration, which in fact is negative but its absolute value is shown in Figures 16 and 17. The actuator voltages beyond $200 \mathrm{~V}$ increase the vibration level at $16 \mathrm{~Hz}$. Hence, the $\mathrm{OV}$ at $16 \mathrm{~Hz}$, based on the harmonic analysis of Figures 16 and 17, is 200 V. Figure 20 is the transient analysis of Figures 16 and 17 at $16 \mathrm{~Hz}$ that confirms that $\mathrm{OV}$ for active vibration suppression for this system at $16 \mathrm{~Hz}$ is $200 \mathrm{~V}$. Figures 16 and 17 also show that, e.g., at $32 \mathrm{~Hz}$ the vibration amplitude decrease for actuator voltages of $160,180,200$, and $220 \mathrm{~V}$, and then beyond $220 \mathrm{~V}$ the actuator starts increasing the vibration $180^{\circ}$ out-of-phase with the structural vibration. The voltages beyond $220 \mathrm{~V}$ increase the vibration level at $32 \mathrm{~Hz}$. Hence, the OV at $32 \mathrm{~Hz}$, based on the harmonic analysis of Figures 16 and 17, is $220 \mathrm{~V}$. Figure 21 is the transient analysis of Figures 16 and 17 at $32 \mathrm{~Hz}$ that confirms that the OV for active vibration suppression for this system at $32 \mathrm{~Hz}$ is $220 \mathrm{~V}$. 
Next, Mode II was considered. Figure 22 shows the mode shape of the second natural frequency at $298.23 \mathrm{~Hz}$. Figure 23 gives displacement responses of the composite beam tip, for various actuator voltages. It can be seen that for the entire spectrum of $260-340 \mathrm{~Hz}$ around the second natural frequency the $\mathrm{OV}$ is $20 \mathrm{~V}$. This is shown more closely in Figure 24. A peak in Figure 23 roughly indicates the system Mode II natural frequency.

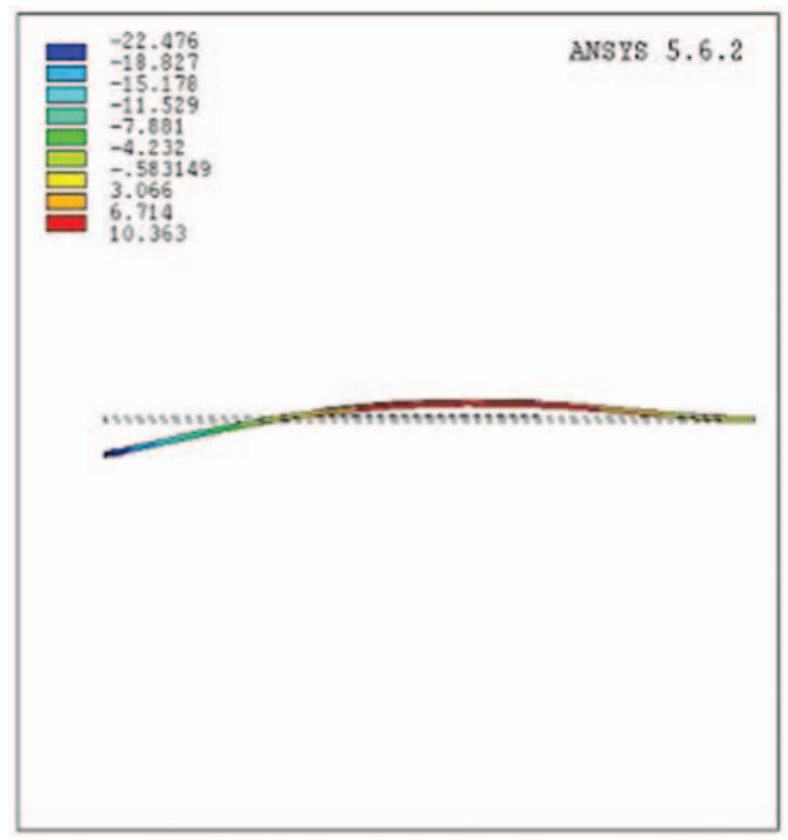

Figure 22. ACP Mode II, $298.23 \mathrm{~Hz}$, modal analysis.

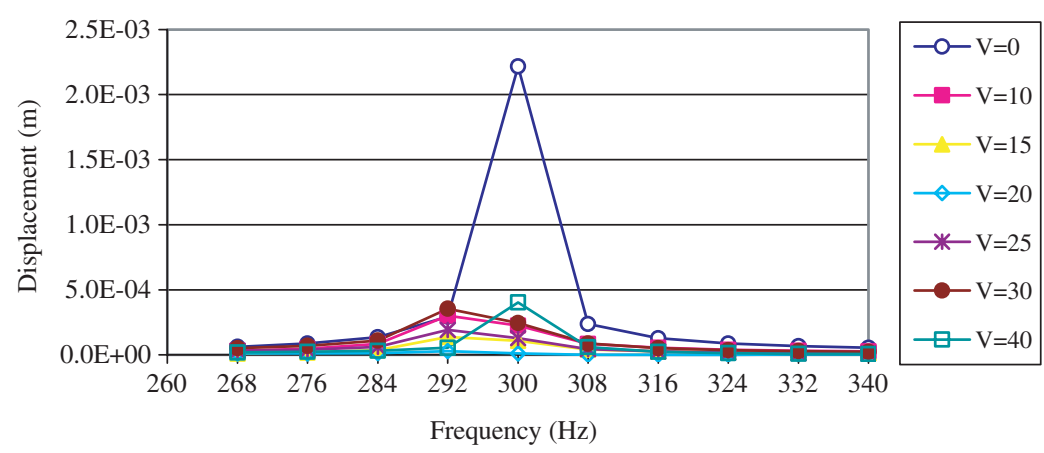

Figure 23. Vibration suppression of ACP Mode II, $298.23 \mathrm{~Hz}$, harmonic analysis, $260-340 \mathrm{~Hz}$. 


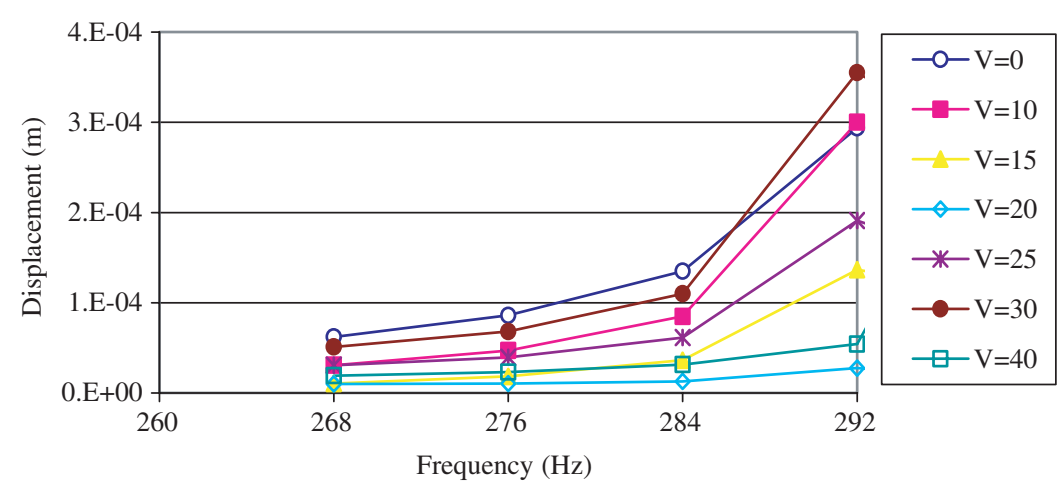

Figure 24. Vibration suppression of ACP Mode II, $298.23 \mathrm{~Hz}$, harmonic analysis, 260$292 \mathrm{~Hz}$.

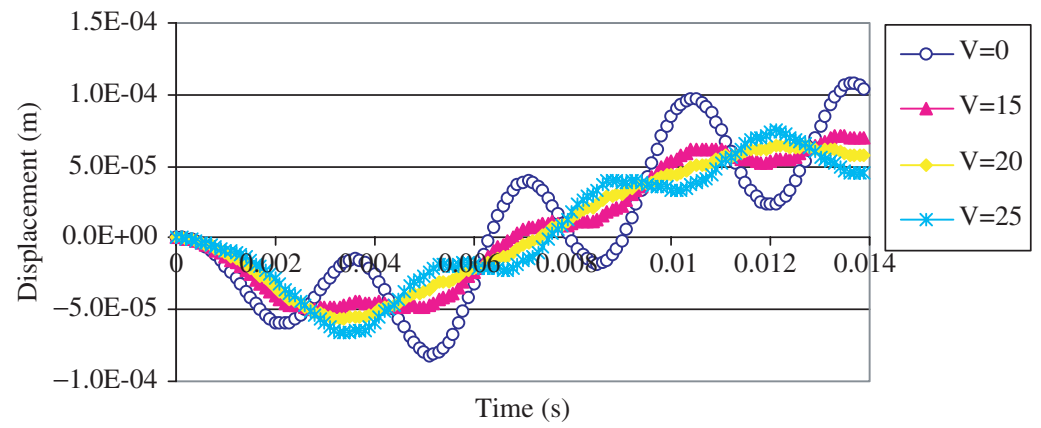

Figure 25. Transient analysis of Figure 24 at $268 \mathrm{~Hz}$ for ACP.

Again, the frequency differences of the peaks observed in Figure 23 decreases with the frequency increment refinement. Figures 25 and 26 are transient analyses of Figure 24 at 268 and $284 \mathrm{~Hz}$, respectively, and they indicate that again the $\mathrm{OV}$ for these frequencies is $20 \mathrm{~V}$.

Third, Mode III was considered. Figure 27 shows the mode shape of the third natural frequency at $832.42 \mathrm{~Hz}$. Figure 28 gives displacement responses of the composite beam tip, for various actuator voltages. A peak in Figure 28 roughly indicates the system Mode III natural frequency. The shift of the peak to the left when both external and internal loads are applied simultaneously, in Figure 28, is somewhat larger than the other cases. This could be attributed to the fact that the piezo patch is located at the center of the beam where the node of the system Mode III natural frequency modal shape exists. Once again, the frequency differences of the peaks observed in Figure 28 decreases with the frequency increment refinement. 


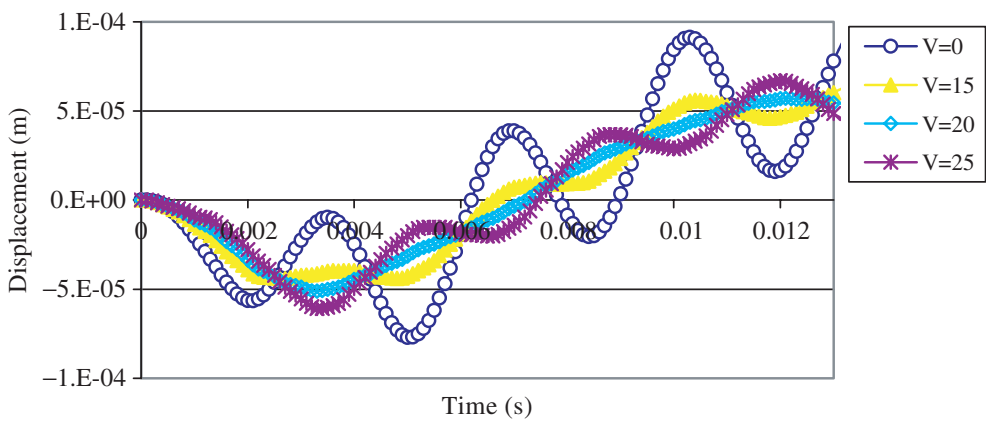

Figure 26. Transient analysis of Figure 24 at $284 \mathrm{~Hz}$ for ACP.

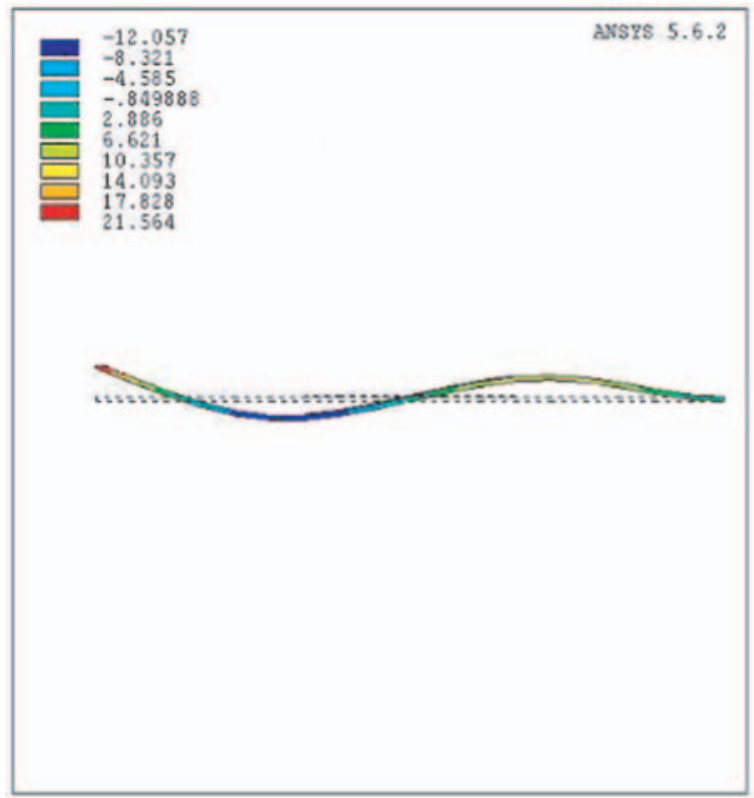

Figure 27. ACP Mode III, $832.42 \mathrm{~Hz}$, modal analysis.

Figure 28 shows that the actuator optimum voltage for frequencies below Mode III natural frequency of $832.42 \mathrm{~Hz}$, is $100 \mathrm{~V}$ but does not have a significant effect on the vibration of the structure in this range. The piezoelectric is more effective for active vibration suppression in the range beyond natural frequency, which is shown in Figure 29 for the $840-875 \mathrm{~Hz}$ range, with $\mathrm{OV}$ of about $80 \mathrm{~V}$. Once again, a transient analysis was performed at $854 \mathrm{~Hz}$ of Figure 29 and similar results were obtained 


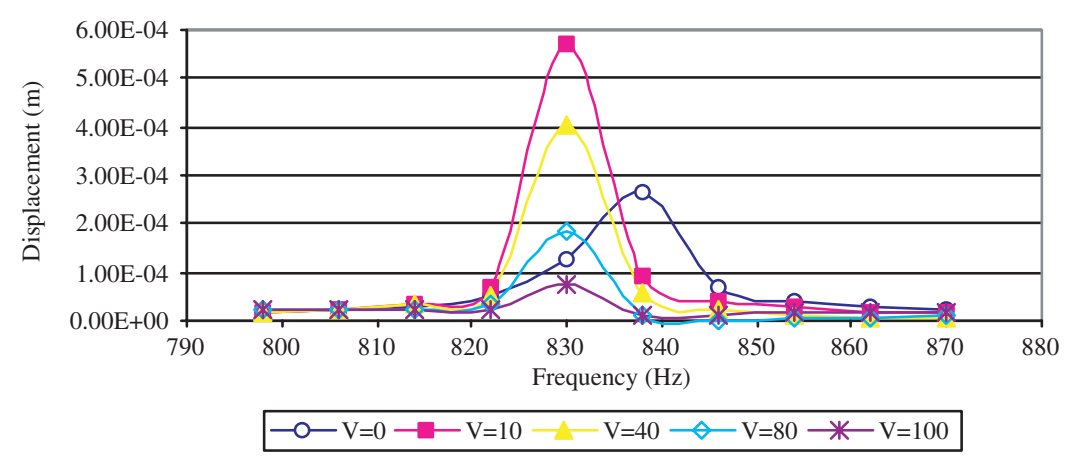

Figure 28. Vibration suppression of ACP Mode III, $832.42 \mathrm{~Hz}$, harmonic analysis, $790-880 \mathrm{~Hz}$.

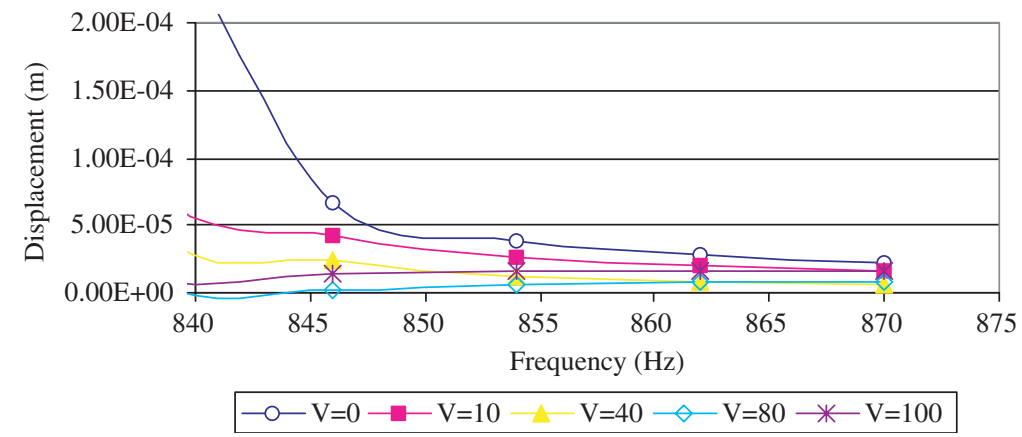

Figure 29. Vibration suppression of ACP Mode III, $832.42 \mathrm{~Hz}$, harmonic analysis, $840-875 \mathrm{~Hz}$.

(not shown here for brevity). The shift of the natural frequency between the uncontrolled and controlled responses in Figure 28 is believed to be due to the fact that the piezo patch for Mode III is located at the node of the mode shape here (Figure 27).

Finally, Mode IV was considered. Figure 30 shows the mode shape of the fourth natural frequency at $1763 \mathrm{~Hz}$. Figures 31 and 32 show displacement responses of the composite beam tip, for various actuator voltages, when the piezo is located at the center and the tip of the beam, respectively. These studies showed that the $\mathrm{OV}$ was about $10 \mathrm{~V}$ and more effective to the right of the Mode IV natural frequency, when the piezo was at the center. The OV was found to be about $2.5 \mathrm{~V}$ when the piezo was at the tip. Next, the actuator was moved to the root (i.e., close to the clamp end) of the beam and the results are given in Figures 33-35. The OV was found to be $10 \mathrm{~V}$ for this case. Similar results were obtained from transient analysis. Again, the shift of the peaks in Figure 33 decreases with frequency increment refinement. 


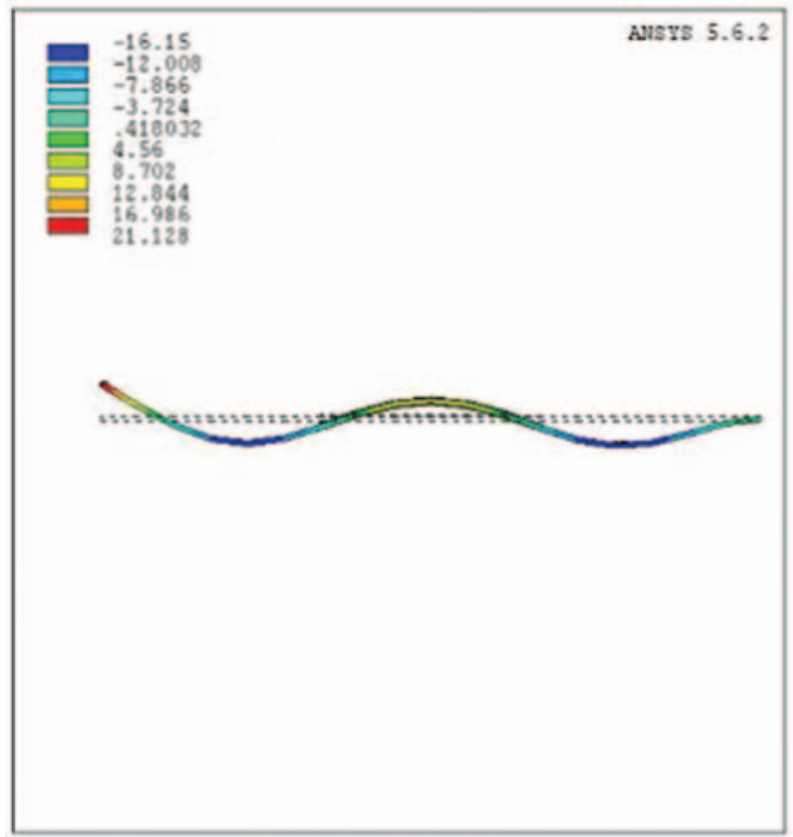

Figure 30. Mode IV, $1763 \mathrm{~Hz}$, modal analysis, ACP.

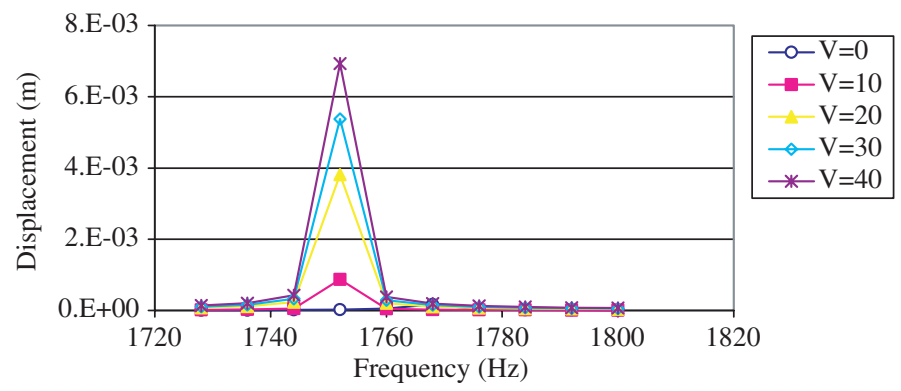

Figure 31. Active vibration suppression of ACP Mode IV, $1763 \mathrm{~Hz}$, harmonic analysis with the actuator at the center for $1720-1800 \mathrm{~Hz}$.

\section{Optimum Voltage for the ACP Lateral Vibration Suppression using Experiments}

To verify the accuracy of the finite element results in form of required piezoelectric actuator voltages necessary to perform active vibration suppressions, comparisons between the experimental results and those 


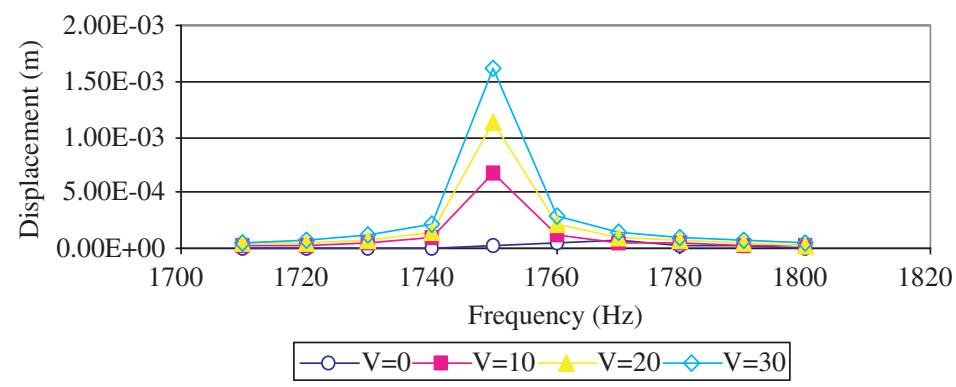

Figure 32. Active vibration suppression of ACP Mode IV, $1763 \mathrm{~Hz}$, harmonic analysis with the actuator at the tip for $1710-1800 \mathrm{~Hz}$.

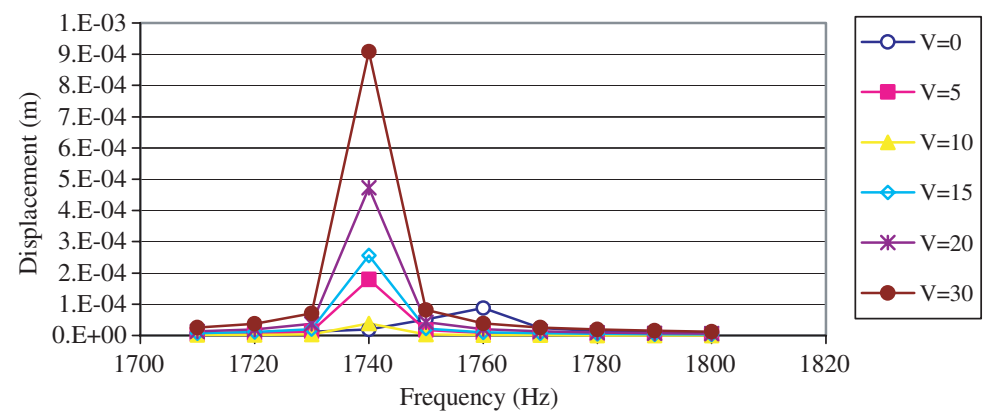

Figure 33. Active vibration suppression of ACP Mode $I V, 1763 \mathrm{~Hz}$, harmonic analysis, actuator at the root for $1710-1800 \mathrm{~Hz}$.

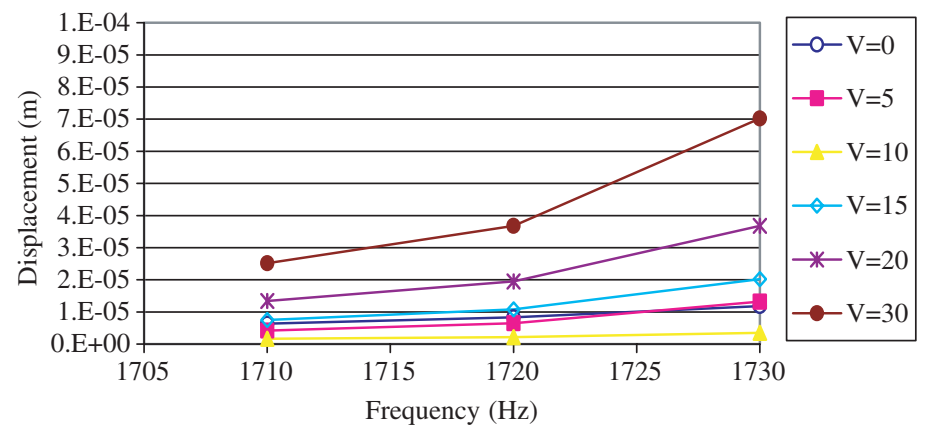

Figure 34. Active vibration suppression of ACP Mode $\mathrm{N}, 1763 \mathrm{~Hz}$, harmonic analysis, actuator at the root for $1710-1730 \mathrm{~Hz}$.

obtained from the FEAs were performed. Here, a composite cantilevered beam with two non-collocated surface-mounted piezoelectric flat patches [53] one acting as a shaker (at the center) and the other as an actuator (at the root) was modeled using ANSYS finite element modeling and analysis. 


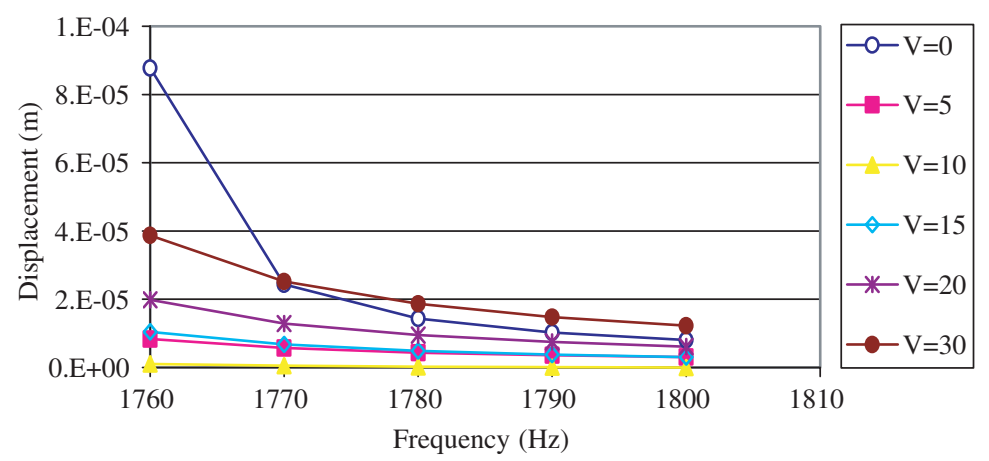

Figure 35. Active vibration suppression of ACP Mode IV, $1763 \mathrm{~Hz}$, harmonic analysis, actuator at the root for $1760-1800 \mathrm{~Hz}$.

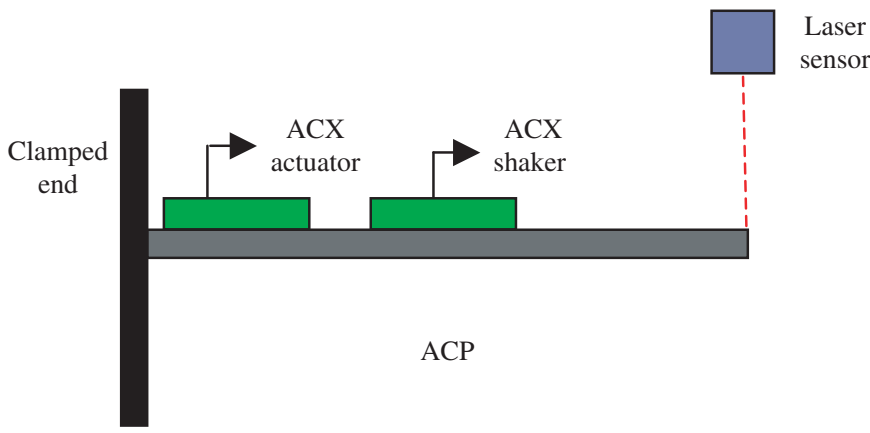

Figure 36. Schematic of the ACP active lateral vibration suppression test setup.

Therefore, here, the external loading was generated by the piezoelectric shaker placed at the beam center/midpoint and the internal loading was produced by the actuator that was placed near the fixed end of the beam (i.e., root). The lateral displacements of the beam free tip were measured numerically as well as experimentally (using a laser sensor). The piezoelectric shaker was excited by supplying a positive harmonic voltage to its positive electrode while its negative electrode was grounded. Figure 36 shows this experimental setup schematically.

It should be noted that, in Figure 14, the piezoelectric patch located at the center functions as the actuator (or the internal loading), and the external loading is applied on the beam tip laterally. For Figure 36, the experimental uncontrolled and controlled beam tip displacements were measured and the results are compared with the FEA in the following. First, a modal analysis was performed with the first experimental natural frequency at $65.8 \mathrm{~Hz}$ and 


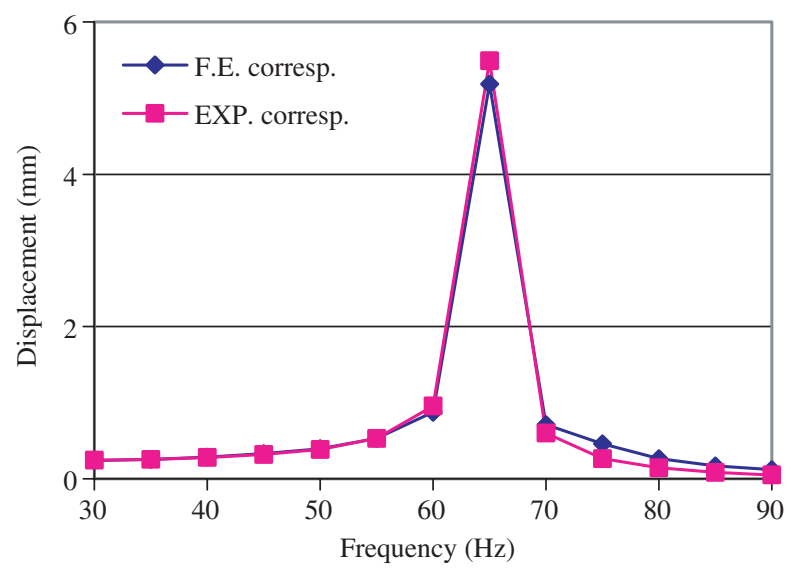

Figure 37. Uncontrolled ACP harmonic displacement comparison between experimental and FEA results, shaker voltage at center is $100 \mathrm{~V}$.

corresponding FEA result at $66.374 \mathrm{~Hz}$ with a percentage of error equal to $0.86 \%$. Next, harmonic experiments and FEA were performed and the results were compared. Figure 37 shows the uncontrolled harmonic displacement comparison between the experimental and FEA results when a peak voltage value equivalent to $100 \mathrm{~V}$ is supplied to the piezoelectric shaker located at the center (Figure 36). The maximum percentage of displacements discrepancy between the FEA and experimental results associated with all frequencies between $30-90 \mathrm{~Hz}$ did not exceed $10 \%$. Also, the natural frequency values obtained from the harmonic and modal analyses as well as the experiments were consistent.

Figure 38 shows the uncontrolled harmonic displacement comparison between the experiment and FEA results when the peak voltage value equivalent to $100 \mathrm{~V}$ was supplied to the piezoelectric actuator located at the beam root (Figure 36). Once again, the first natural frequency for both the experiment and FEA was consistent with previous harmonic and modal results. For this case, the percentage of displacements discrepancy between the FEA and experimental results associated with all frequencies between $30-90 \mathrm{~Hz}$ was less than $10 \%$. These results indicate that an excellent agreement between the uncontrolled experimental displacements and those obtained from the FEA is established.

Figure 39 shows the comparison between the experimentally measured actuator control voltages at any frequency needed for the active vibration suppression and those determined using FEA. Here, harmonic experiments and FEA were performed with a peak voltage equivalent to $30 \mathrm{~V}$ applied to the piezoelectric shaker located at the center (Figure 36) and the required 


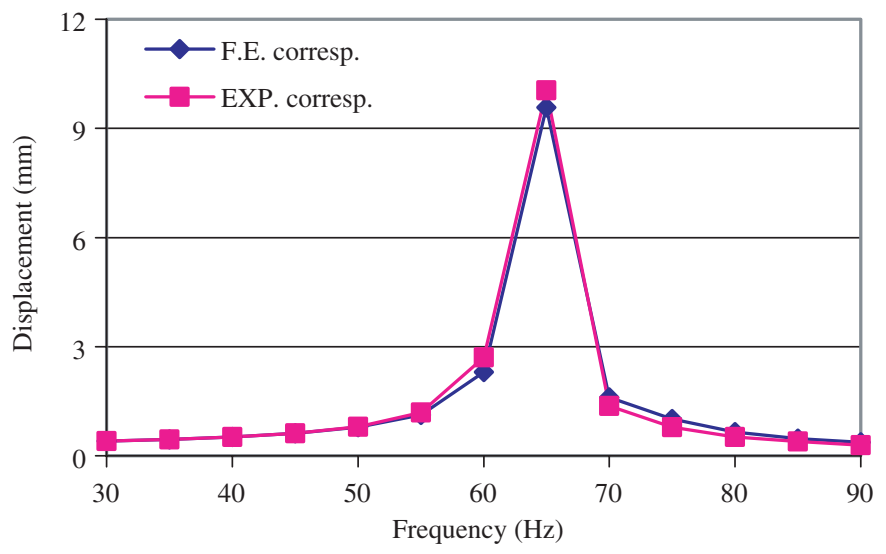

Figure 38. Uncontrolled ACP harmonic displacement comparison between experimental and FEA results, actuator voltage at root is $100 \mathrm{~V}$.

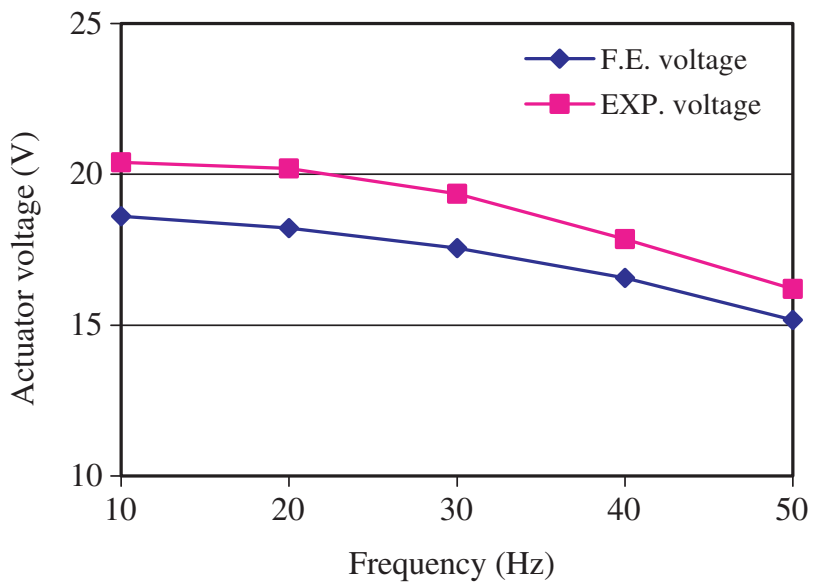

Figure 39. Comparison between experimental and FEA actuator voltages (root), shaker at center with $\mathrm{V}=30 \mathrm{~V}$.

piezoelectric actuator (located at the root, see Figure 36) voltages needed to perform active vibration suppression by $100 \%$ of vibration reduction were measured experimentally and numerically. The control voltage comparison study between the experimental and FEA results was conducted and measured at five frequencies $10-50 \mathrm{~Hz}$ with an increment of $10 \mathrm{~Hz}$ and the results are reported in Figure 39. Figure 39 is summarized in Table 2 where the percentage of error between the experimental results and those obtained from the FEA is less than $10 \%$ for the frequency range considered in these experiments. 
Table 2. Comparison between experimental and FEA actuator voltages with percentage error.

\begin{tabular}{lccc}
\hline $\begin{array}{l}\text { Frequency } \\
(\mathbf{H z})\end{array}$ & $\begin{array}{c}\text { FEA } \\
(\mathbf{V})\end{array}$ & $\begin{array}{c}\text { Experiments } \\
(\mathbf{V})\end{array}$ & $\begin{array}{c}\text { Error (\%) } \\
\mathbf{1 0 0}(\operatorname{Exp}-\mathrm{FEA}) / \text { Exp }\end{array}$ \\
\hline 10 & 18.61 & 20.4 & 8.77 \\
20 & 18.22 & 20.2 & 9.80 \\
30 & 17.55 & 19.35 & 9.30 \\
40 & 16.57 & 17.85 & 7.17 \\
50 & 15.18 & 16.2 & 6.30 \\
\hline
\end{tabular}

\section{EFFECTS OF ACTUATOR LOCATION ON THE OPTIMUM VOLTAGE}

The effects of the actuator location on the OV were investigated for the first four modes. Three actuator locations were considered: (1) when the actuator was at the 'Center' of the composite beam (Figure 14), (2) when the actuator was at the 'Tip' of the composite beam (where the external load has been applied throughout this work), and (3) when the actuator was at the 'Root' of the composite beam (where the beam is clamped). A table is developed to tabulate the effects of the actuator location on the OV for the first four modes, and is given by Table 3 .

In Table 3, a single number means an $\mathrm{OV}$ exists for the entire range enveloping the natural frequency under consideration, which can be called a constant voltage $(\mathrm{CV})$ meaning that the optimum peak voltage is a constant value for the entire range of frequency under consideration. 'Right' or 'Left' means that the actuator is more effective for active vibration suppression for the right or left portion of the natural frequency, respectively, within the range under consideration. In case of 'Right' or 'Left,' there are other values of OVs for the opposite region of the 'Right' or 'Left,' but are not as effective as the reported right or left regions in terms of the active vibration suppression. Table 3 shows that for Modes I and III the 'Root' location performs the best for two reasons. First, one OV (i.e., a CV) works for the whole frequency range of Modes I and III, and second the level of these voltages are minimum among the three locations for each Mode I or Mode III. For Modes II and IV, the 'Tip' location works the best for the same reasons. It is believed that the better performance of the 'Tip' location is due to the relative large size of the piezo-patch, i.e., $5.08 \mathrm{~cm}$ or $2 \mathrm{in}$ long, compared with the length of the entire beam, i.e., $15.24 \mathrm{~cm}$ or $6 \mathrm{in}$. Therefore, the best location for a piezoelectric patch actuator depends on the range of the frequency operation and mode shape of the system. 
Table 3. Effects of the actuator location on the ACP optimum voltage (OV).

\begin{tabular}{lccccc}
\hline Modes & $\begin{array}{c}\text { OV/tip } \\
(\mathbf{V})\end{array}$ & $\begin{array}{c}\text { OV/center } \\
(\mathrm{V})\end{array}$ & $\begin{array}{c}\text { OV/root } \\
(\mathrm{V})\end{array}$ & $\begin{array}{c}\text { Natural } \\
\text { frequency (HZ) }\end{array}$ & Mode shape \\
\hline Mode I & 700 (Left) & 200 & 80 & 46.34 & 298.23 \\
Mode II & 10 & 20 & 40 & 832.42 \\
Mode III & 20 (Right) & 80 (Right) & 20 & 1763.00 \\
Mode IV & 2.5 & 10 (Right) & 10 & -
\end{tabular}

However, if the frequency range of interest spans over all first four modes and only one piezo-patch and location is desirable for such a beam, then Table 3 suggests that the 'Root' location is the best overall, since (a) the level of the maximum OV (i.e., $80 \mathrm{~V}$ in this case) needed to actively suppress all four modes of vibration is minimum among the three locations, and (b) the sum of OVs for all four modes for the 'Root' location is minimum among the three cases considered here. Hence, it is believed that the use of OV for vibration suppression and the development of tables such as Table 3 have practical values in the design of smart structures. Although, the OV determined here for various cases have been found by gradually increasing the level of the actuator control voltage and monitoring the residual vibration, a direct approach to precisely and directly determine the OV for various frequencies and load levels for both ACP and ACS are reported by Ghasemi-Nejhad and co-workers [19,59]. The results from both approaches compare well. It should be mentioned that the element mesh convergence studies were performed for all FEA studies presented here with a convergence criteria of less than $5 \%$ for the field dependent variable under consideration, e.g., displacement, etc.

\section{CONCLUSIONS}

A guideline is provided for the use of piezoelectric stack and monolithic patch actuators in finite element analysis. The results from the analytical formulae compared with the manufacturer's experimental data and the obtained finite element results in this work show excellent agreements. Next, an active vibration suppression study employing ANSYS finite element analysis (FEA) was employed to determine the optimum voltage (OV) that when applied to a piezoelectric actuator can actively suppress the structural 
vibration for a wide range of frequency enveloping a particular natural frequency under consideration. Both axial and lateral active vibration suppressions were demonstrated using an active composite strut model and an active composite panel, respectively. It is demonstrated here that the experimental and FEA results for both axial, using an active composite strut, and lateral, using an active composite panel, are in good agreements for the frequency ranges considered here. In addition, the effects of the actuator location on the vibration suppression and the level of OV was examined and reported here. This study showed that the optimum location of the actuator depends on the operation frequency range and mode shape for the system under consideration.

\section{ACKNOWLEDGMENTS}

The authors acknowledge the financial support of the Office of Naval Research for the adaptive damping and positioning using intelligent composite active structures (ADPICAS) under government grant number of N00014-00-1-0692. The authors also thank Dr. Richard Russ and Dr Kougen $\mathrm{Ma}$ for the sample preparation and testing of the active composite panels.

\section{REFERENCES}

1. Anderson, E.H., Moore, D.M. and Fanson, J.L. (1990). Development of an Active Truss Element for Control of Precision Structures, Optical Engineering, 29(11): 1333-1341.

2. Newnham, R.E. and Ruschau, G.R. (1993). Electromechanical Properties of Smart Materials, Journal of Intelligent Material Systems and Structures, 4(3): 289-294.

3. Boyd, J., Tupper Hyde, T., Osterberg, D. and Davis, T. (2001). Performance of a Launch and On-orbit Isolator, In: Proc. SPIE Conf. on Smart Structures and Integrated Systems, Vol. 4327, Newport Beach, CA, pp. 433-440.

4. Quenon, D., Boyd, J., Buchele, P., Self, R., Davis, T., Hintz, T. and Jacobs, J. (2001). Miniature Vibration Isolation System for Space Applications, In: Proc. SPIE Conf. on Industrial and Commercial Applications of Smart Structure Technologies, Vol. 4332, Newport Beach, CA, pp. 159-170.

5. Fujita, T., Nonaka, H., Yang, C.S., Konda, H., Mori, Y. and Amasaka, Y. (1998). Active Vibration Control of Frame Structures with Smart Structure using Magnetostrictive Actuator, In: Regelbrugge, M.E. (ed.), Proceedings of SPIE, Smart Structures and Materials, Smart Structures and Integrated Systems, Vol. 3329(2), San Diego, CA, pp. 584-595.

6. Song, G., Vlattas, J., Johnson, S.E. and Agrawal, B.N. (1999). Active Vibration Control of a Space Truss using PZT Stack Actuator, In: Washington, G. and Redmond, J. (eds), Proceedings of ASME International Mechanical Engineering Congress and Exposition, Adaptive Structures and Material Systems, New York, NY, AD-59/MD-87, pp. 263-268.

7. Dekens, F.G. and Neat, G.W. (1999). Mirco-Precision Interferometer: Pointing System Performance in on-orbit Disturbance Environment, In: Wereley, N.M. (ed.), Proceedings of SPIE, Smart Structures and Materials, Smart Structure and Integrated System, Vol. 3668(1), Newport Beach, CA, pp. 426-439. 
8. O’Brien, J.F., Goullioud, R. and Neat, G.W. (1998). Micro-Precision Interferometer: Evaluation of New Disturbance Isolation Solutions, In: Davis, L.P. (ed.), Proceedings of SPIE, Smart Structures and Materials, Passive Damping and Isolation, Vol. 3327, San Diego, CA, pp. 387-398.

9. Hyde, T.T. and Davis, L.P. (1998). Vibration Reduction for Commercial Optical Intersatellite Communication Links, In: Regelbrugge, M.E. (ed.), Proceedings of SPIE, Smart Structures and Materials, Smart Structures and Integrated Systems, Vol. 3329(1), San Diego, CA, pp. 94-105.

10. Masters, B.P. and Crawley, E.F. (1997). An Experimental Investigation of Optimized Precision Optical Controlled-Structures, In: Regelbrugge, M.E. (ed.), Proceedings of SPIE, Smart Structures and Materials, Smart Structures and Integrated Systems, Vol. 3041, San Diego, CA, pp. 348-359.

11. Huang, S.H., Natori, M.C., Umetani, Y., Nakai, S. and Katukura, H. (1997). An Object Oriented Modeling Approach to Intelligent Variable Geometry Trusses, Journal of Intelligent Material Systems and Structures, 8(2): 158-172.

12. Darby, A.P. and Pellegrino, S. (1997). Inertail Stick-Slip Actuator for Active Control of Shape and Vibration, Journal of Intelligent Material Systems and Structures, 8(12): 1001-1011.

13. Wada, B.K., Fanson, J.L., Chen, G.S. and Kuo, C.P. (1990). Adaptive Structures in Space, In: Proceedings of 'US-Japan Workshop on Smart/Intelligent Materials and Systems, Honolulu, HI, pp. 59-81.

14. Burleigh Instruments Ltd. (2001). Company Technical Literature.

15. Roberts, D. (1999). Development of a Linear Piezoelectric Motor Based upon the Inchworm Model, In: Wereley, N.M. (ed.), Proceedings of SPIE, Smart Structures and Materials, Smart Structure and Integrated System, Vol. 3668(2), Newport Beach, CA, pp. 705-716.

16. Frank, J., Koopmann, G.H., Chen, W. and Lesieutre, G.A. (1999). Design and Performance of a High Force Piezoelectric Inchworm Motor, In: Wereley, N.M. (ed.), Proceedings of SPIE, Smart Structures and Materials, Smart Structure and Integrated System, Vol. 3668(2), Newport Beach, CA, pp. 717-723.

17. Galante, T., Frank, J., Bernard, J., Chen, W., Lesieutre, G.A. and Koopmann, G.H. (1998). Design, Modeling, and Performance of a High Force Piezoelectric Inchworm Motor, In: Regelbrugge, M.E. (ed.), Proceedings of SPIE, Smart Structures and Materials, Smart Structures and Integrated Systems, Vol. 3329(2), San Diego, CA, pp. 756-767.

18. Clephas, B. and Janocha, H. (1997). New Linear Motor with Hybrid Actuator, In: Regelbrugge, M.E. (ed.), Proceedings of SPIE, Smart Structures and Materials, Smart Structures and Integrated Systems, Vol. 3041, San Diego, CA, pp. 316-325.

19. Doherty, K.M. and Ghasemi-Nejhad, M.N. (2005). Performance of an Active Composite Strut for an Intelligent Composite Modified Stewart Platform for Thrust Vector Control, Journal of Intelligent Material Systems and Structures, 16(4): 335-354.

20. Ma, K. and Ghasemi-Nejhad, M.N. (2005). Simultaneous Precision Positioning and Vibration Suppression of Flexible Manipulators, Proceedings of The First International Workshop on Advanced Smart Materials and Smart Structures Technology Honolulu, HI, pp. 636-643.

21. Ghasemi-Nejhad, M.N. (2002). Active Composite Panels and Active Composite Struts as Building Blocks of Adaptive Structures, In: Proc. of JSME/ASME International Conference on Materials and Processing, Smart Materials and Structures, Honolulu, Hawaii, pp. 432-440.

22. Ma, K. and Ghasemi-Nejhad, M.N. (2005). Simultaneous Precision Positioning and Vibration Suppression of Reciprocating Flexible Manipulators, Journal of Smart Structures and Systems, 1(1): 13-27. 
23. Suleman, A., Moniz, P.A. and Costa, A.P. (1999). Experimental Flutter and Buffeting Suppression using Piezoelectric Actuators and Sensors, In: Washington, G. and Redmond, J. (eds), Proceedings of ASME International Mechanical Engineering Congress and Exposition, Adaptive Structures and Material Systems, New York, AD-59/ MD-87, pp. 293-299.

24. Yoshikawa, S.H., Farrell, M., Warkentin, D., Jacques, R. and Saarmaa, E. (1999). Monolithic Piezoelectric Actuator and Vibration Dampers with Interdigital Electrodes, In: Wereley, N.M. (ed.), Proceedings of SPIE, Smart Structures and Materials, Smart Structure and Integrated Systems, Vol. 3668(2), Newport Beach, CA, pp. $578-585$.

25. Lee, Y.Y., Mei, C. and Huang, J.-K. (1998). Control of Random Vibrations of Composite Plates with Piezoelectric Actuators, In: Sirkis, J. and Washington, G. (eds), Proceedings of ASME International Mechanical Engineering Congress and Exposition, Adaptive Structures and Material Systems, New York, AD-57/MD-83, pp. 109-127.

26. Etienne-Cummings, R., Pourboghrat, F., Maruboyina, H.K., Abrate, S. and Dhali, S. (1998). Architecture for Distributed Actuation and Sensing using Smart Piezoelectric Elements, In: Regelbrugge, M.E. (ed.), Proceedings of SPIE, Smart Structures and Materials, Smart Structures and Integrated Systems, Vol. 3329(2), San Diego, CA, pp. 708-716.

27. Proulx, B., St-Amant, Y. and Cheng, L. (1998). Active Control of Plates Using Integrated Piezoceramic Elements of Various Shapes: Modeling and Experiments, In: Regelbrugge, M.E. (ed.), Proc. of SPIE, Smart Structures \& Materials, Smart Structures \& Integrated Systems, Vol. 3329(2), San Diego, CA, pp. 735-746.

28. Carpenter, M.J. (1997). Using Energy Methods to Derive Beam Finite Elements Incorporating Piezoelectric Materials, J. of Intelligent Mat. Systems and Struct., 8(1): 26-40.

29. Chandrashekhara, K. and Varadarajan, S. (1997). Adaptive Shape Control of Composite Beams with Piezoelectric Actuators, J. of Intelligent Mat. Systems and Structure, 8(2): 112-124.

30. Yang, S.M. and Jeng, J.A. (1997). Vibration Control of a Composite Plate with Embedded Optical Fiber Sensor and Piezoelectric Actuator, Journal of Intelligent Material Systems and Structures, 8(5): 393-401.

31. Ogden, J.W. and Grandhi, R.V. (1996). Optimal Placement of a Piezoelectric Patch on Plate Structures for Vibration Suppression, In: Aatre, V.K., Varadan, V.K. and Varadan, V.V. (eds), Proceedings of SPIE, Smart Structures and Materials, Structures and MEMS, Vol. 3321, Bangalore, India, pp. 170-184.

32. Agrawal, B.N. and Elshafei, M.A. (1997). Shape Control of Composite Material Plates using Piezoelectric Actuators, In: Hariz, A., Varadan, V.K., and Reinhold, O. (eds), Proc. of SPIE, Smart Materials, Structures and Integrated Sys., Vol. 3241, Adelaide, Australia, 300-311.

33. Wilson, D.G., Parker, G.G., Starr, G.P. and Roboinett, R.D. (1998). Robust Position Control of Flexible Adaptive Structures with Embedded PZT Actuators, In: Sirkis, J. and Washington, G. (eds), Proc. of ASME International Mechanical Engineering Congress and Exposition, Adaptive Structures and Material Systems, New York, AD-57/MD-83, pp. 209-216.

34. Martin, J.W., Main, J.A. and Nelson, G.C. (1998). Shape Control of Deployable Membrane Mirrors, In: Sirkis, J. and Washington, G. (eds), Proceedings of ASME International Mechanical Engineering Congress and Exposition, Adaptive Structures and Material Systems, New York, AD-57/MD-83, pp. 217-223.

35. Mall, S. and Hsu, T.L. (1999). Electromechanical Fatigue Behavior of Graphite/Epoxy Laminate Embedded with Piezoelectric Actuator, In: Wereley, N.M. (ed.), Proceedings of SPIE, Smart Structures and Materials, Smart Structure and Integrated System, Vol. 3668(2), Newport Beach, CA, pp. 770-774. 
36. Wang, D. and Carman, G.P. (1998). Combined Electrical and Mechanical Fatigue of Piezoelectric Ceramics undergoing Polarization Switching for Large Displacement Actuation, In: Regelbrugge, M.E. (ed.), Proceedings of SPIE, Smart Structures and Materials, Smart Structures and Integrated Systems, San Diego, CA, Vol. 3329(1), pp. $210-221$.

37. Ghasemi-Nejhad, M.N., Russ, R. and Pourjalali, S. (2005). Manufacturing and Testing of Active Composite Panels with Embedded Piezoelectric Sensors and Actuators, Journal of Intelligent Materials Systems and Structures, 16(4): 319-334.

38. Ma, K. and Ghasemi-Nejhad, M.N. (2003). Simultaneous Precision Positioning and Vibration Suppression of Smart Structures: Adaptive Control Methods and Comparisons, In: Proceedings of 42nd IEEE Conference on Decision and Control, Vol. 6, Maui, Hawaii, pp. 6386-6391.

39. Ma, K. and Ghasemi-Nejhad, M.N. (2004). Frequency-Weighted Adaptive Control for Simultaneous Precision Positioning and Vibration Suppression of Smart Structures, Journal of Smart Materials and Structures, 13(5): 1143-1154.

40. Ma, K. and Ghasemi-Nejhad, M.N. (2005). Adaptive Simultaneous Precision Positioning and Vibration Control of Intelligent Composite Structures, Journal of Intelligent Materials Systems and Structures, 16(2): 163-174.

41. Morgan Matrocs, Inc. (1996). Company Technical Literature.

42. Stewart, D. (1965). A Platform with Six Degrees of Freedom, In: Proceedings of Institute of Mechanical Engineers, Vol. 180(15), London, pp. 371-386.

43. Ghasemi-Nejhad, M.N. and Doherty, K.M. (2002). Modified Stewart Platform for Spacecraft Thruster Vector Control, Aerospace Division, Adaptive Structures, In: Proceedings of ASME International Mechanical Engineering Congress and Exposition, New Orleans, LA, Paper No. IMECE2002-34032, pp. 1-8.

44. Inman, J.D., Gern, F.H., Robertshaw, H.H., Kapania, R.K., Pettit, G., Natarajan, A. and Sulaeman, E. (2001). Comments on Prospects of Fully Adaptive Aircraft Wings, In: Proc. SPIE Conf. on Industrial and Commercial Applications of Smart Structures Technologies, Vol. 4332, Newport Beach, CA, pp. 1-9.

45. Kudva, J.N., Sanders, B., Pinkerton-Florance, J. and Garcia, E. (2001). Overview of the DARPA/AFRL/NASA Smart Wing Phase 2 Program, In: Proc. SPIE Conf. on Industrial and Commercial Applications of Smart Structures Technologies, Vol. 4332, Newport Beach, CA, pp. 383-389.

46. Martin, C.A., Scherer, L.B., Flanagan, J.S. and Carpenter, B.F. (2001). Design, Fabrication, and Testing of Scaled Wind Tunnel Model for the Smart Wing Phase 2 Program, In: Proc. SPIE Conf. on Industrial and Commercial Applications of Smart Structures Technologies, Vol. 4332, Newport Beach, CA, pp. 399-406.

47. Wang, D.P., Bartley-Cho, J.D., Martin, C.A. and Hallam, B.J. (2001). Development of High-Rate, Large Deflection, Hingeless Trailing Edge Control Surface for the Smart Wing Wind Tunnel Model, In: Proc. SPIE Conf. on Industrial and Commercial Applications of Smart Structures Technologies, Vol. 4332, Newport Beach, CA, pp. 407-418.

48. Moses, R.W., Wieseman, C.D., Bent, A.A. and Pizzochero, A.E. (2001). Evaluation of New Actuators in a Buffet Loads Environment, In: Proc. SPIE Conf. on Industrial and Commercial Applications of Smart Structures Technologies, Vol. 4332, Newport Beach, CA, pp. 10-21.

49. Ashour, O.N. and Nayfeh, A.H. (2001). Nonlinear Control of Plate Vibrations, In: Proc. SPIE Conf. on Smart Structures and Integrated Systems, Vol. 4327, Newport Beach, CA, pp. 669-679.

50. Takahashi, K., Bansaku, K., Sanda, T. and Matsuzaki, Y. (2001). Sound and Vibration Control Tests of Composite Panel using Piezoelectric Sensors and Actuators, In: Proc. SPIE Conf. on Smart Structures and Integrated Systems, Vol. 4327, Newport Beach, CA, pp. $680-687$. 
51. Ghasemi-Nejhad, M.N. and Soon, C. (2003). Design and Analysis of an Adaptive Circular Composite Panel with Embedded Sensors/Actuators for Active Vibration Suppression, In: Proceedings of Fourth Canadian International Composites Conference (CANCOM 2003), Ottawa, Canada, Paper No. 046.

52. Ghasemi-Nejhad, M.N. and Sakagawa, R. (2003). Design and Analysis of an Adaptive Tubular Composite Housing for Active Vibration Suppression, In: Proc. of Fourth Canadian International Composites Conference (CANCOM 2003), Ottawa, Canada, Paper No. 045.

53. ACX. (2001). Active Control eXperts, www.acx.com.

54. ANSYS, Inc. (2004). ANSYS User's Manual, Canonsburg, PA, www.ansys.com.

55. Cady, W.G. (1964). Piezoelectricity, McGraw-Hill, New York, NY.

56. Physiks Instruments (2001). Company Technical Literature.

57. Meirovitch, L. (1967). Analytical Methods in Vibration, The Macmillan Co., New York.

58. Ng, R.K.H., Yousefpour, A., Uyema, M. and Ghasemi-Nejhad, M.N. (2002). Design, Analysis, Manufacture, and Test of Shallow Water Pressure Vessels Using E-Glass/Epoxy Woven Composite Material for a Semi-Autonomous Underwater Vehicle, Journal of Composite Materials, 36(21): 2443-2478.

59. Russ, R. and Ghasemi-Nejhad, M.N. (2002). Vibration Suppression Schemes for Active Composite Strut and Panel, In: Rao, V.S. (ed.), Proceedings of SPIE, Smart Structures and Materials; Modeling, Signal Processing and Control, Vol. 4693, San Diego, CA, pp. $418-429$. 